\title{
The Use of Omic Technologies Applied to Traditional Chinese Medicine Research
}

\author{
Dalinda Isabel Sánchez-Vidaña, ${ }^{1}$ Rahim Rajwani, ${ }^{2}$ and Man-Sau Wong ${ }^{3}$ \\ ${ }^{1}$ Department of Rehabilitation Sciences, The Hong Kong Polytechnic University, Hung Hom, Kowloon, Hong Kong \\ ${ }^{2}$ Department of Health Technology and Informatics, The Hong Kong Polytechnic University, Hung Hom, Kowloon, Hong Kong \\ ${ }^{3}$ Department of Applied Biology and Chemical Technology, The Hong Kong Polytechnic University, Hung Hom, Kowloon, Hong Kong \\ Correspondence should be addressed to Man-Sau Wong; man-sau.wong@polyu.edu.hk
}

Received 28 July 2016; Revised 23 October 2016; Accepted 24 October 2016; Published 31 January 2017

Academic Editor: Fabio Firenzuoli

Copyright (C) 2017 Dalinda Isabel Sánchez-Vidaña et al. This is an open access article distributed under the Creative Commons Attribution License, which permits unrestricted use, distribution, and reproduction in any medium, provided the original work is properly cited.

\begin{abstract}
Natural products represent one of the most important reservoirs of structural and chemical diversity for the generation of leads in the drug development process. A growing number of researchers have shown interest in the development of drugs based on Chinese herbs. In this review, the use and potential of omic technologies as powerful tools in the modernization of traditional Chinese medicine are discussed. The analytical combination from each omic approach is crucial for understanding the working mechanisms of cells, tissues, organs, and organisms as well as the mechanisms of disease. Gradually, omic approaches have been introduced in every stage of the drug development process to generate high-quality Chinese medicine-based drugs. Finally, the future picture of the use of omic technologies is a promising tool and arena for further improvement in the modernization of traditional Chinese medicine.
\end{abstract}

\section{Natural Products and Traditional Chinese Medicine in Drug Discovery}

Since ancient times, plants have been an essential element for the prevention and treatment of a wide variety of diseases. Historically, natural products represent one of the most important reservoirs of structural and chemical diversity for the generation of leads in the drug development process $[1,2]$. The tendency to develop drugs from natural sources can be clearly observed in a study of the sources of drugs between 1981 and 2010. The study showed that about $45 \%$ of the approved drugs by the FDA were natural products or natural products derivatives $[3,4]$.

In the past years, the use of herbal preparations has gained attention in European and Asian countries. Only in Europe, about 100 million people make use of traditional and complementary medicine. Furthermore, the increasing popularity of traditional and alternative medicine is observed in Africa, Asia, Australia, and North America [5-7]. In academia and industry, a growing number of researchers have shown interest in the development of drugs based on Chinese herbs [2].
Traditional Chinese Medicine (TCM) is a medical system for the prevention and treatment of diseases that focuses on the patient rather than the disease when compared to the Western medicine. The main principle by which TCM works is the use of herbs for the restoration of the yinyang imbalance that results in disease [2]. Despite the increasing popularity and interest on TCM, researchers face a challenging task when gathering scientific evidence and clinical validation of Chinese based herbal remedies. The main bottlenecks in the study of TCM include quality control, the identification of cellular targets, mechanism of action, and clinical validation due to the variability of the individual herbal ingredients, the complexity of herbal formulations, and the combined action on different targets (Figure 1) $[6,8]$.

Novel advanced technologies are needed to improve separation methods, quality control, standardization techniques, screening, the study of the mechanism of action of individual compounds, and clinical validation assays. In this sense, the application of omic technologies in TCM research is a promising approach to assist in the modernization of TCM and to address the complex challenges encountered in TCM 


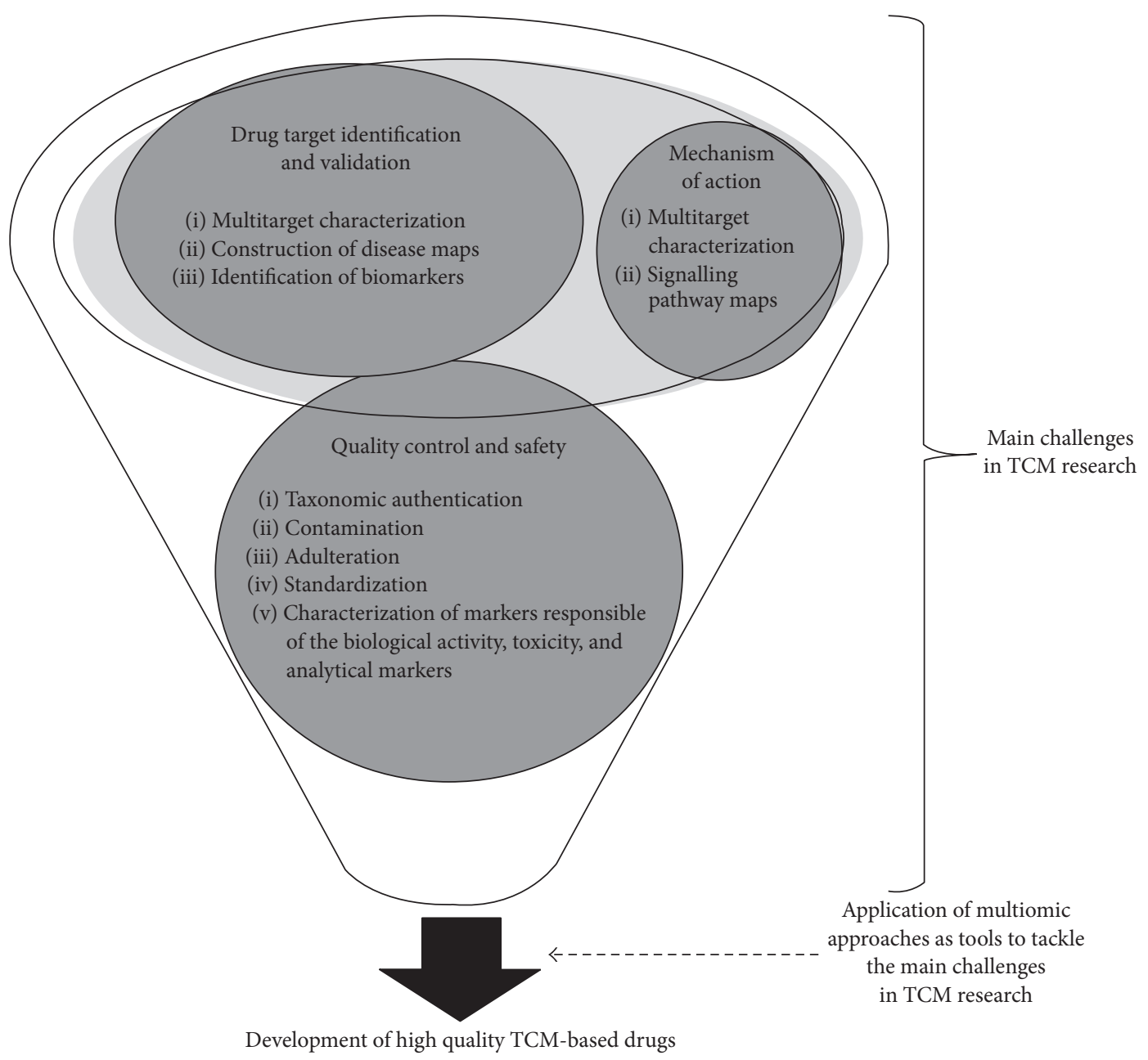

FIGURE 1: Application of omic technologies to tackle the main challenges in TCM research.

research. Therefore, the aim of this review is to give a general overview of the use of omic technologies as promising and powerful tools in TCM research.

\section{Omic Approaches in TCM Research}

The rapidly evolving technology has led to the development of research tools to assist a more comprehensive study of biological systems. In TCM, researchers have gradually introduced the most recent technological advances trying to overcome the most common bottlenecks in TCM research. By analyzing the emergence and evolution of the current technologies, their potential application in TCM research can be better understood.

A significant breakthrough in technological advances was the completion of the Human Genome Project which is considered one of the greatest scientific achievements of the past century [9]. The genomic revolution in the Human Genome Project was the platform that contributed to the development and improvement of technologies for identification of drug targets, target validation, and disease etiology $[10,11]$. Some of the technological advances include Sanger DNA sequencing, nanotechnology, miniaturization and automation technologies, DNA-based genetic markers, cloning systems, polymerase chain reaction, and genotyping of single nucleotide polymorphism. The techniques developed during the Human Genome Project have played an essential role in the understanding of biological processes [11].

Despite the significant contribution of genomic studies, the need to bridge the sequence information for the identification of potential therapeutic targets with the physiology and pathology of an organism using novel sophisticated approaches became a clear and pivotal task [10]. One way to fill the gap between genomic information and biological processes was the use of combined strategies from several levels together with analytical technologies and improved computational power. The integration of technology, bioinformatics, and molecular biology approaches at different organizational levels is comprised in systems biology and provides a complete picture to understand the molecular mechanisms $[12,13]$.

The postgenomic era was a pivotal stage for the emergence of "omic" studies in biological research representing the beginning of the systems biology era. Data generated by omic studies are described as the wholeness of living systems that result in useful information after the application of 


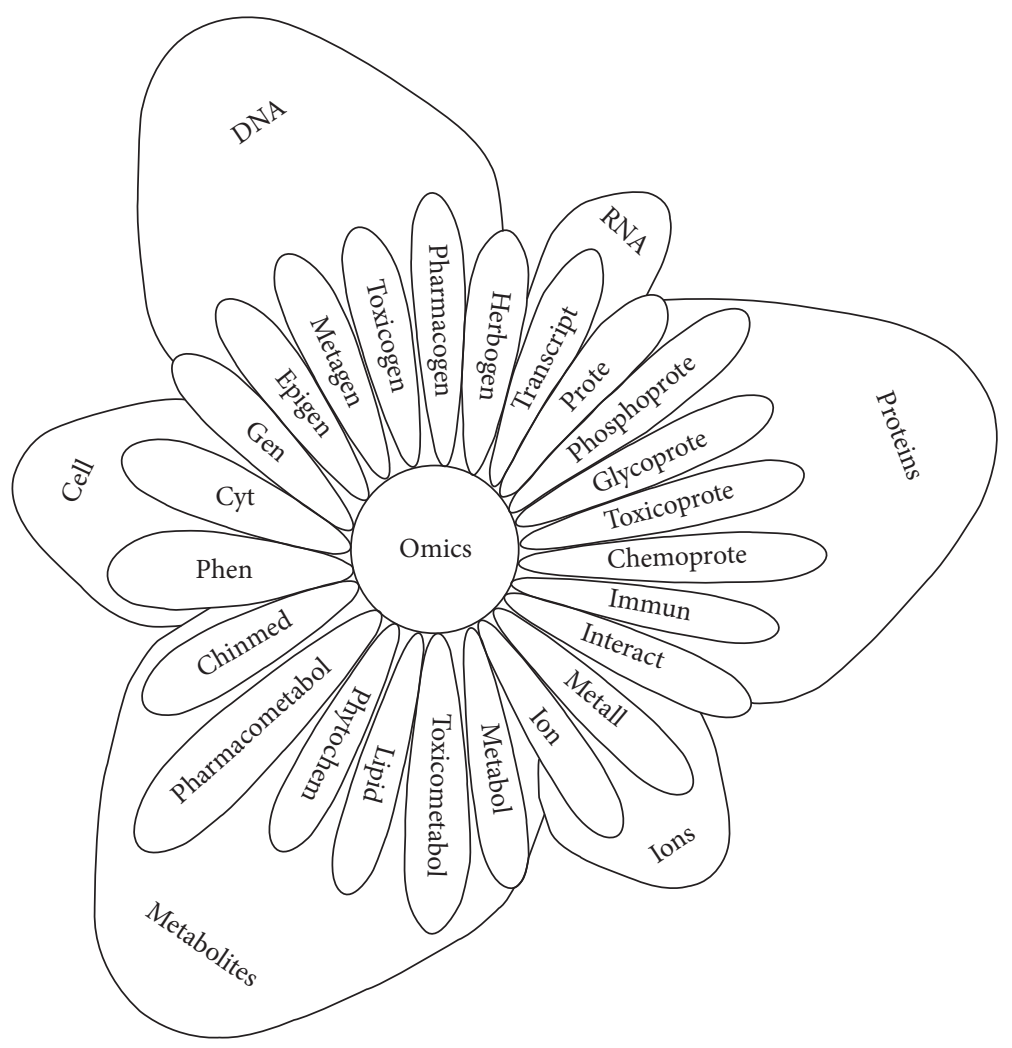

FIGURE 2: Omic approaches and their area of study in systems biology.

bioinformatic analyses [14]. The organizational levels in systems biology include genomics, transcriptomics, proteomics, and metabolomics [12]. Furthermore, new omic concepts and technologies have been introduced comprising more specialized areas of study in systems biology [14] (Figure 2).

The analytical combination of information from each omic approach is crucial for understanding the working mechanisms of cells, tissues, organs, and organisms as well as the mechanisms of disease $[11,15]$. Visualization and analysis of combined multiomic data increase, in a large scale, the comprehensive understanding of biological processes [14]. Therefore, application of omic approaches in TCM represents powerful tools for the development of high-quality herbderived drugs.

2.1. Omic Approaches at DNA Level. Genes and gene products act as a complex interconnected network in synchrony with a wide variety molecular system pathways rather than acting independently. Since the establishment of omics approaches, omic technologies have been applied in different areas of biotechnology, drug discovery, and biomedical research including TCM. However, a close analysis of the omic research published in the past ten years shows that the use of omic technologies in TCM has not been fully explored [16]. Therefore, special attention should be paid to link the advantages of omic techniques with the complex concerns encountered in TCM research.

Another omic approach at DNA level is epigenomics. Epigenetic studies focus on the reversible heritable modifications in gene expression that do not involve any change in the DNA sequence $[14,17]$. As an omic approach, the aim of epigenomics is to identify gene alterations through the analysis of epigenetic changes that take place in the whole genome [14]. Despite promising findings, the application of epigenomics in TCM needs further exploration [17].

Metagenomic studies involve the analysis of a collection of genes from the environment that are related to the host physiology [14]. This approach is of particular interest when studying the relationship between the gut microflora and the pathophysiological state of the host and drug metabolism [18]. So far, the contribution of metagenomics in TCM research represents a novel and promising area of study that contributes to the modernization of TCM.

The study of the alterations in gene expression upon exposure to chemicals to identify potential genetic toxicants and monitor their cellular mechanisms is the main focus of toxicogenomics $[14,19]$. Toxicogenomics comprises the dynamics between genes and environmental stress in disease etiology and development [20].

Pharmacogenomics aims to identify and analyze genes involved in the response to drugs to assess interindividual variability and susceptibility to adverse drug reactions [21, 22]. Pharmacogenomics studies provide valuable information to determine doses for the effective and safe use of medications [14]. In the field of TCM research, databases have been constructed including active compounds found in Chinese herbs which are categorized using chemical informatics protocols. Multidisciplinary integration of data 
generated by other omic approaches provides a wider and more understanding overview of pharmacogenomics applied to TCM research.

Herbogenomics, also referred as botanogenomics, is a novel concept that makes use of genomic and proteomic comparative analysis for the study of the biological effect of herbs [23]. This concept has emerged as an attempt to introduce a more specialized platform particularly focused on herbal remedies $[23,24]$. The comparison between treated and control groups gives an insight into the genome and proteome alterations that take place upon treatment with herb-derived compounds or herbal preparations.

2.2. Omic Approach at RNA Level. Transcriptomics comprises the study of the complete set of messenger RNA under specific conditions in any given cell; it is also known as the study of transcripts [12, 25]. By using genetic association databases, it is possible to make comparisons between the gene expression profile under treatment with certain herbal formulae and the profile of disease state or any known drug. Such comparisons can be used to predict unknown physiological effects, unwanted interactions, or side effects [16]. Nonetheless, more transcriptomic information combined with multiomic technologies should be included in strategies for modernization of TCM.

2.3. Omic Approaches at Protein Level. The above-mentioned omic approaches have contributed to the understanding of biological processes for the evaluation and validation of TCM. Another promising technology developed that has strongly emerged as a powerful tool for the assessment of physiological events is proteomics. Since the introduction of the term proteomics for the first time 20 years ago, proteomic technologies have rapidly evolved and being integrated into several stages in the pharmaceutical research and development [26]. Proteomic studies focus on the whole population of proteins in a specific cell type, tissue, body fluid, or a whole organism at a given time $[14,27]$. The concept of proteomics can be described from the point of view of TCM in which the Qi or vital essence is the result of the overall performance of the proteome [28].

The downstream complexity of mechanisms that lead to a specific biological effect is not directly related to the number of genes. Instead, other gene expression mechanisms such as posttranslational modifications and alternative splicing play an important role in protein variation. It has been estimated that about $35 \%$ of human genes undergo alternative splicing which means that the traditional one gene one protein hypothesis should be adjusted to a one gene-many protein model $[13,25]$. As a consequence, proteomics has a particularly important impact on the discovery of novel drug targets [26].

Phosphorylation is considerably the most commonly found posttranslational modification in proteins accounting for about 17,500 phosphorylated gene products in humans [29]. Phosphorylation of proteins plays a pivotal role in crucial cell mechanisms including gene expression, cell signaling, metabolism, cell growth, and cell differentiation [14]. In addition, alterations in protein phosphorylation have been directly involved in disease etiology and progression, but only a small number of proteins, about 350 proteins, have been experimentally validated [29]. Despite the enormous potential of phosphoproteomics technologies, the difficulties encountered in the development of sophisticated, sensitive, and reliable phosphoproteomic methods may contribute to the slow introduction of these techniques in TCM studies.

Similarly, as phosphoproteomics, glycoproteomics comprises the study of proteins with another important posttranslational modification in cell processes, namely, glycosylation. Glycosylation of proteins occurs in about $25 \%$ of the human proteins and nearly 4,500 proteins have being detected to undergo glycosylation [29]. However, some estimations reveal that glycosylation may occur in about $50 \%$ of all human proteins. Glycosylated proteins participate in cellular functions including cell adhesion, cell immunity, protein translation, and protein degradation among other cellular functions [14]. Although glycoproteomic technologies are currently available and have shown great potential in drug discovery and drug development, the application of these technologies in the development of high-quality TCMderived drugs needs to be explored.

Another omic approach that focuses on the proteome is toxicoproteomics which is used to evaluate the effect of the exposure to toxic agents in cells and tissues at qualitative and quantitative level. The proteome profiling upon xenobiotic exposure allows prediction of toxic responses to herbal components [30].

Chemoproteomics applies function-based proteomics to study the protein structure and their interaction with chemicals. The proteins subjected to chemoproteomic studies require carefully optimized conditions to conserve protein structure, posttranslational modifications, and even interactions with regulatory proteins $[14,31]$. Chemoproteomic approaches can be categorized as global and targeted chemoproteomic strategies. The global chemoproteomics approach focuses on the cellular response, namely, protein expression or any specific posttranslational modification, upon treatment with a compound of interest [31]. At the end of the analytical process, bioinformatic tools are applied to characterize protein structure and function [14].

Immunomics focus on the regulatory mechanisms of the immune system on pathogens from antigen recognition to the immune response caused by the antigens presented to the immune machinery of the host [14, 32]. Although the immunomodulatory effects of several Chinese herbs are well known and documented, the use of modern technology to assess the close interactions and molecular mechanisms triggered by TCMs using immunomics is still in a very early stage [33].

As mentioned above, the use of multiple omic approaches allows a broader and more detailed understanding of biological phenomena from different points of view. The complexity and a large amount of data generated by each individual omic approach have led to the emergence of a new omic tool to combine, analyze, and interpret multiomic data. The result of the analytical combination of the enormous amount of data generated by different omic approaches is called integrome and it is the main focus on interactomics [34]. Interaction 
networks can be constructed using bioinformatic tools in interactomic studies to track changes in the traits of networks. The main application of interactomic studies so far has been in drug discovery [14].

2.4. Omic Approaches at Metabolite Level. Metabolomic studies include the qualitative and quantitative analysis of a large number of metabolites and their dynamics in a given biological system $[12,35]$. The aim of metabolomics is the measurement of the global, dynamic, and downstream homeostatic effect in biochemical pathways caused by specific stimuli [16]. The stimuli that induce changes in the metabolic profile can be categorized as internal factors such as genetic modifications, as well as external factors such as environmental and pharmaceutically induced effects [12]. The metabolic profiling can also provide important information about the pathophysiological, pharmacodynamics, and pharmacokinetic condition [16]. Any change in the living system in terms of physiology, pathology, or any other disturbance will lead to changes in the metabolome [14].

The metabolic state of an individual is influenced by environmental, genetic, and gut microbiome factors. Comparative studies of the metabolic profiles before and after drug exposure provide valuable information about the treatment outcome and the effect of drugs on metabolism. Pharmacometabolomics is currently applied in pharmacology, drug discovery, and development and personalized therapy [36]. In recent years, pharmacometabolomic studies have been widely applied in TCM studies contributing to a better understanding of the metabolic profile-TCM effect.

The omic discipline that combines metabolomics and toxicology in comparative analyses of endogenous metabolite profiles in a normal state and during and after drug treatment is toxicometabolomics [37]. Since safety is one of the main concerns in TCM research, metabolomics and toxicometabolomics are very useful tools to assess the toxicological processes in TCMs [14]. For instance, several studies investigated the mechanistic basis of aristolochic acid nephrotoxicity using 1H-NMR spectroscopy, GC-MS, and LC-MS [38-41]. In this regard, toxicometabolomic approach uncovered that aristolochic induced nephrotoxicity in aristolochic acid treated rats may be arising from decreased levels of prostaglandins resulting in a reversible vasoconstrictive state and kidney lesions [38-41]. A similar investigation was also conducted to investigate the nephrotoxic effect of longterm usage of ricin-based products. Ricin is a water-soluble glycoprotein based key toxin of Ricinus communis (also known as castor-oil plant). Long-term treatment with ricin was shown to induce perturbations in multiple metabolic pathways including amino-acid metabolism and oxidative stress which partly explains the observed nephrotoxicity [42]. Furthermore, a GC-MS study investigated hepatotoxic effects of triptolide (the active anti-inflammatory ingredient of Tripterygium wilfordii) and discovered changes in $B$ oxidation pathway [43]. Together, these toxicometabolomic studies demonstrated the potential of metabolomic technologies for understanding TCM-based toxicity.

Lipids play essential roles in biological processes from energy reservoirs and structural cellular components to elements in cell-signaling pathways [44]. Studies on the lipidome, the lipid profile in biological systems, have shown that disturbances in lipid metabolites are closely related to the development of diseases such as obesity, Alzheimer's disease, diabetes, and some infectious diseases [14, 45]. However, analytical challenges have been encountered in lipidomic studies due to the chemically diverse structure of lipids in complex biological mixtures. Therefore, the technologies used in lipidomic studies require constant improvement to provide more sensitive and accurate analysis of the lipid profile in biological samples.

The phytochemome comprises the group of compounds present in plants such as alkaloids, polyphenols, terpenes, sulfides, thiols, plant peptides, and their metabolites. Phytochemomics focuses on the intracellular and extracellular study at different molecular levels, the chemical structure, and mechanism of action of the phytochemome [46]. Phytochemomic analytical approaches use the same methods that are used in metabolomics studies. The main difference between metabolomics and phytochemomics is that the latter only focuses on the chemical analysis of compound present in plants. The phytochemomic concept has not been widely used. Therefore, it is more common to find in the literature the term metabolomics when studying phytochemicals.

The focus of chinmedomics is to investigate the biological action, synergistic effect, and metabolic profile of Chinese formulae. Chinmedomics has shown great potential when studying TCM since it introduces the holistic concept of TCM combined with the most sophisticated analytical tools $[47,48]$.

The technologically driven advances in chinmedomics have been used to address the efficacy and safety concerns in TCM research $[47,49]$. To ensure the therapeutic effect of TCM treatment, the serum pharmacochemistry analysis is assessed to collect information about the mechanism of action, the interaction among the components of the formulae, and the assessment of the relationship between syndrome and TCM.

2.5. Omic Approaches at Ion Level. Metallomics is defined as the comprehensive quantitative and qualitative analysis of an entire set of metals and metalloid species within a cell, tissue, or the whole organisms [50]. Since it is well known that a lot of proteins require the presence of metals such as copper, ion, zinc, and molybdenum as cofactors to exert their biological actions, metallomics significantly contributes to studying protein function [14].

Crucial physiological processes such as cellular signaling, metabolism, enzymatic activity, and transmembrane transport involve the action of ions [14]. The ionome, a concept introduced 10 years ago that refers to the study of the mineral nutrients and trace elements in a cell or organism, is the focus of ionomic studies $[51,52]$. The quantitative measurement of changes in the mineral composition of a specific tissue or organism as a response to internal or external stimuli, namely, normal or pathological physiological processes, drug effect, or genetic modifications, is carried out in ionomic studies [53]. 
2.6. Omic Approaches at Cellular Level. The phenotype is the whole set of physical and biochemical characteristics of a living organism as a result of interaction with genetic and environmental factors $[14,54]$. In the disease state, the disease manifestation, progression, severity of the symptomatology, and response to therapy are closely related to the genetic component of the organism and all together defines the disease phenotype [54].

Phenome is the whole set of expressed traits in a defined population associated with the influence of genetic of environmental factors $[14,55]$. Phenomics focuses on the understanding and monitoring of the changes in the phenome as a result of environmental and genetic factors [14]. By studying the phenotype, the biological processes that occur as a result of genetic and environmental influences can be reflected in the genomic architecture [55]. Phenomic studies are difficult to carry out regarding TCM since it is complex to identify the compounds responsible for the therapeutic effect due to the rich chemical content of herbal remedies. However, the integration, analysis, and understanding of phenomic data applied to TCM studies represent a valuable tool in TCM research.

The study of the phenotype at a cellular level for the understanding of molecular disease networks is the focus of cytomics. In order to gain more understanding of the molecular processes at a cellular level, the human cytome project was conceived [56]. However, the application of these technologies in TCM research is quite limited.

As discussed above, the diversity of omic approaches provides a wide variety of technological tools that are applied to TCM research. In addition, the potential applications of some omic technologies in TCM research should be further explored. In Table 1, a summary of all the omic technologies discussed above and their application in different areas of the drug discovery and drug development process in TCM research is presented.

Omic technologies can be applied to the study of a wide variety of diseases as shown in Table 2 . Therefore, the potential use of omic technologies in TCM research has a wide scope of application.

\section{Quality Control and Safety of TCM Using Omic Technologies}

A critical concern in TCM research is to ensure quality, safety, and efficacy to meet the quality standard requirements [93]. In the regulatory context, the assessment of herbal medicinal products has been included in protocols and guidelines developed by regulatory authorities and monitoring agencies such as the European Medicines Agency, the European Food Safety Authority, the Chinese State Food and Drug Administration, the Herbal Medicinal Product Committee (European scientific committee), and the World Health Organization. The latest has published a series of test methods for identification, purity, and content assessment in the quality control Methods for Medicinal plant materials [94-97]. The European Medicines Agency has developed guidelines including the guideline on good agricultural and collection practice for starting materials of herbal origin, guideline on quality of herbal medicinal products/traditional herbal medicinal products, guideline on the quality of combination herbal medicinal products/traditional herbal products, and the guideline on specifications: test procedures and acceptance criteria for herbal substances, herbal preparations, and herbal medicinal products/traditional herbal medicinal products [98]. In order to meet the criteria established by local and international regulatory agencies for quality assurance, safety, and efficacy in traditional medicine, omic technologies have played a crucial role in facilitating the sensitive and efficient evaluation of herbal-based medicines.

In TCM, the diversity and number of components responsible for the biological activity make the analytical procedure a challenging task. However, emerging technologies and improved methods have contributed to facilitating the quality control of TCMs. Some of the technologies applied in the characterization of metabolites for quality control include NMR-based metabolic fingerprinting, capillary electrophoresis, HPLC, gas chromatography, HPLC-PDA-ESI/MS, HPLCDAD-ESI/MS, GC/MS, GCxGC-qMS, TOF/MS, GCxGCTOF/MS, MALDI-TOF/MS, HLPC/UV, TLC, ultra-TLC, UPLC, UPLC-Q/TOF-MS, IT-TOF-MS, capillary zone electrophoresis (CZE), capillary electrochromatography (CEC), pressurized CEC, micellar electrokinetic chromatography, turbulent flow chromatography (TFC), and HPLC/ESI/MS [93, 99-101]. Some of the above-mentioned technologies including MALDI-TOF-MS and UPLC-Q/TPG/MS have been adapted to high-throughput settings to support a simple, quick, sensitive, and cost-effective analysis of TCMs [80, $100,102]$. More recently, technology such as miniaturized and integrated microchips, that is, as Herbochip ${ }^{\circledR}$, DNA chip, protein chip, and DNA chip, have been developed to be applied in high-throughput screening of active ingredients [93]. Therefore, DNA barcoding technologies have also shown to facilitate the standardization, identification, and quality control of herb-based medicines [103]. $1 \mathrm{H} \mathrm{NMR}$ spectroscopy is an analytical tool that allows the detection of proton-bearing compounds without making any distinction based on the chemical compound class. This technique is used to identify and quantify metabolites in a mixture in a one-step process which facilitates the analysis in highthroughput settings $[104,105]$ and is a powerful tool in the quality control of herbal remedies. For example, $1 \mathrm{H}$ NMR was used to determine the metabolic profile of the Chinese formula Danggui Buxue Tang traditionally used in the treatment of menopausal symptoms. The analysis of the $1 \mathrm{H}$ NMR spectra of the herbal formula revealed a distinctive metabolic profile of the decoction when compared to the individual components of the formula which provides pivotal information for the standardization and quality control of the herbal remedy [105]. UPLC-MS/MS is being widely employed for the analysis of samples of complex composition since it provides high resolution for the detection of compounds present in herbal mixtures without the need for pure standards [106].

The metabolite characterization is not only useful for assessment of efficacy and safety by determination of the compounds responsible for the biological activity or side effects, but also it is essential for the standardization during the 
TABLE 1: Omic technologies and their areas of application in TCM research.

\begin{tabular}{|c|c|c|}
\hline Omic approach & Area of application & Ref. \\
\hline Genomics & $\begin{array}{c}\text { Drug target identification } \\
\text { Genetic disease markers } \\
\text { Genome manipulation for target validation }\end{array}$ & [57-59] \\
\hline Epigenomics & $\begin{array}{c}\text { Study of epigenetic mechanisms of } \\
\text { phytochemicals in the regulation of gene } \\
\text { expression }\end{array}$ & {$[17]$} \\
\hline Metagenomics & $\begin{array}{l}\text { Study of the relationship between the gut } \\
\text { microflora and the pathophysiological state of the } \\
\text { host and drug metabolism }\end{array}$ & {$[18]$} \\
\hline Toxicogenomics & $\begin{array}{c}\text { Mechanism of toxicity (chronic, carcinogenic } \\
\text { effect, and secondary effects of drugs) } \\
\text { Biomarkers of toxicity and disease biomarkers } \\
\text { Gene expression profiling of contaminants of } \\
\text { herbal remedies for quality control } \\
\text { Detection of toxic adulterants in herbal } \\
\text { preparations } \\
\text { Screening tests for prediction of toxicity of herbs } \\
\text { in the drug development process }\end{array}$ & {$[14,20,21]$} \\
\hline Pharmacogenomics & $\begin{array}{c}\text { Candidate genes with potential relevance in the } \\
\text { efficacy and safety profile of TCMs } \\
\text { Drug targets } \\
\text { Identification of active compounds linking gene } \\
\text { and disease information }\end{array}$ & {$[60]$} \\
\hline Herbonomics & $\begin{array}{l}\text { Mechanism of action of herbal components } \\
\text { Toxicity assessment of herbal remedies }\end{array}$ & {$[23,24]$} \\
\hline Transcriptomics & Prediction of therapeutic potential and safety & {$[16]$} \\
\hline Proteomics & $\begin{array}{c}\text { Therapeutic targets } \\
\text { Exploration of pharmacological effect and } \\
\text { mechanism of multitarget regulatory actions } \\
\text { Quality control and toxicological profile of herbal } \\
\text { remedies } \\
\text { Disease diagnosis } \\
\text { Biomarkers and monitoring of disease progression }\end{array}$ & {$[15,16,61,62]$} \\
\hline Phosphoproteomics & $\begin{array}{l}\text { Study of disease pathogenesis } \\
\text { Disease biomarkers } \\
\text { Drug targets }\end{array}$ & {$[14,63]$} \\
\hline Glycoproteomics & $\begin{array}{c}\text { Identification of aberrant proteins linked to } \\
\text { pathophysiological processes } \\
\text { Diagnosis biomarkers } \\
\text { Mechanism of disease } \\
\text { Drug targets } \\
\end{array}$ & {$[14]$} \\
\hline Toxicoproteomics & $\begin{array}{l}\text { Detection of biomarkers in response to xenobiotic } \\
\text { exposure } \\
\text { Prediction of toxic response to herbal components }\end{array}$ & {$[30]$} \\
\hline Chemoproteomics & $\begin{array}{c}\text { Mechanism of disease } \\
\text { Mechanism of action of compounds of interest }\end{array}$ & {$[14]$} \\
\hline Immunomics & $\begin{array}{c}\text { Drug target } \\
\text { Biomarker identification } \\
\text { Study of immunomodulatory effect of herbs }\end{array}$ & {$[14,62]$} \\
\hline Interactomics & $\begin{array}{c}\text { Drug discovery } \\
\text { Building interaction networks among interacting } \\
\text { molecules }\end{array}$ & {$[14,29]$} \\
\hline
\end{tabular}


TABLE 1: Continued.

\begin{tabular}{|c|c|c|}
\hline Omic approach & Area of application & Ref. \\
\hline Metabolomics & $\begin{array}{c}\text { Pharmacokinetics } \\
\text { Pharmacodynamics } \\
\text { Toxicology } \\
\text { Disease diagnosis } \\
\text { Molecular pathology } \\
\text { Botanic identification } \\
\text { Standardization of herbal remedies } \\
\text { Quality control } \\
\text { Elucidation of toxicological profile of herbal } \\
\text { preparations }\end{array}$ & {$[64]$} \\
\hline Toxicometabolomics & $\begin{array}{c}\text { Toxicity related biomarkers } \\
\text { Molecular pathways involved in toxicological } \\
\text { responses to botanicals }\end{array}$ & [14] \\
\hline Lipidomics & $\begin{array}{c}\text { Mechanism of disease } \\
\text { Drug target discovery } \\
\text { Disease biomarkers }\end{array}$ & {$[14,33,45]$} \\
\hline Phytochemomics & $\begin{array}{c}\text { Mechanism of action of herbal compounds } \\
\text { Quality control of herbs } \\
\text { Production of herb-based medicinal products } \\
\text { Toxicity assessment }\end{array}$ & {$[34]$} \\
\hline Pharmacometabolomics & $\begin{array}{c}\text { Study of phenotype signatures by mapping key } \\
\text { pathways of the metabolic drug effects } \\
\text { Pharmacology } \\
\text { Drug discovery and drug development } \\
\text { Personalized medicine }\end{array}$ & {$[63]$} \\
\hline Chinmedomics & $\begin{array}{c}\text { Mechanism of action and metabolic profile of } \\
\text { Chinese formulae } \\
\text { Efficacy and safety of TCMs } \\
\text { Disease biomarkers }\end{array}$ & {$[35-37]$} \\
\hline Metallomics & $\begin{array}{c}\text { Functional study of metal/metalloid-containing } \\
\text { molecules and metabolites (i.e., genes, } \\
\text { polysaccharides, and proteins) } \\
\text { Mechanism of action of herbs } \\
\text { Disease biomarkers } \\
\text { Toxicological profile } \\
\text { Quality control }\end{array}$ & {$[14,45,46,65]$} \\
\hline Ionomics & $\begin{array}{c}\text { Mechanism of disease } \\
\text { Mechanism of action } \\
\text { Disease biomarkers } \\
\text { Toxicological profile } \\
\text { Quality control }\end{array}$ & {$[50,51]$} \\
\hline Phenomics & $\begin{array}{l}\text { Disease biomarkers } \\
\text { Biomarkers of survival } \\
\text { Therapeutic targets }\end{array}$ & {$[66]$} \\
\hline Cytomics & $\begin{array}{l}\text { Disease biomarkers } \\
\text { Drug targets } \\
\text { Target validation } \\
\text { Personalized medicine } \\
\text { Drug development } \\
\text { Pharmacology } \\
\text { Toxicology }\end{array}$ & {$[14,54,67]$} \\
\hline
\end{tabular}

manufacturing process. Differences in quantity and quality of compounds in TCMs can be due to factors such as the plant of the plant used, storage conditions, agricultural practices (growth conditions, geographic area, and time of harvest, among others), extraction, and preparation methods [15, 35]. Those factors can contribute to the variability in content and quantity of compounds between batches that could affect the pharmacological activity [107]. Therefore, metabolome characterization using the previously mentioned techniques is essential to ensure the development of high-quality TCMs.

Although important technological advances for the analysis of TCMs have been developed and applied, some 
TABLE 2: Examples of application of omic approaches in TCM research per area of study in systems biology.

\begin{tabular}{|c|c|c|c|}
\hline $\begin{array}{l}\text { Level in system } \\
\text { biology }\end{array}$ & Omic approach & Disease/health condition & Results \\
\hline \multirow{3}{*}{ DNA } & Genomics & Cancer & $\begin{array}{l}\text { The different signaling pathways affected by the } \\
\text { compound Kushen injection, a Chinese formula used } \\
\text { for the treatment of different types of cancer, that } \\
\text { contribute to its antitumor activity were identified } \\
\text { including cell proliferation and apoptosis }\end{array}$ \\
\hline & Epigenomics & Cancer & $\begin{array}{l}\text { Gene expression modulatory pathways were elucidated } \\
\text { in cancer models of naturally occurring compounds } \\
\text { such as curcumin isolated from turmeric, } \\
\text { epigallocatechin-3-gallate which is a component of } \\
\text { green tea, genistein isolated from soy, isothiocyanates } \\
\text { present in broccoli, sprouts, and wasabi, lycopene } \\
\text { which is found in tomatoes, and resveratrol present in } \\
\text { grapes, wines, and eucalyptus }\end{array}$ \\
\hline & Metagenomics & $\begin{array}{l}\text { Gut microflora } \\
\text { disturbances }\end{array}$ & $\begin{array}{l}\text { The Chinese formula containing Radix ginseng, } \\
\text { Rhizoma atractylodis macrocephalae, Poria and Radix } \\
\text { glycyrrhizae traditionally used in the treatment of } \\
\text { spleen deficiency showed restoring effects of the gut } \\
\text { ecosystem by modulation of the gut microflora } \\
\text { composition and structure of the intestinal mucosa }\end{array}$ \\
\hline
\end{tabular}

Ref.

Using microarray analysis, it was observed that the components of the three yellows heart-draining

RNA Transcriptomics Liver diseases decoction (San-Huang-Xie-Xin-Tang) exert their liver protective activity by acting on the antiproliferation activity modulated by P53 and DNA damage signaling cascade

The Chinese medicine Patrinia heterophylla, used as an antitumor herb, affected the regulation of proteins involved in energy metabolism, oxidative stress,

Protein Proteomics Leukemia apoptosis, signal transduction, differential induction, and protein biosynthesis which give insights into the antitumor mechanism of action of this herb on leukemia K562 cells

Berberine, a compound isolated from the Chinese herb Coptis chinensis, showed to downregulate high levels of 13 free fatty acids in patients with diabetes type 2 and

Metabolomics Diabetes type 2

Toxicometabolomics

Nephrotoxicity induced by aristolochic acid (compound widely present in botanicals)

Metabolite Lipidomics Hyperlipidemia

Phytochemomics

Cancer

Chinmedomics
Liver disorders dyslipidemia. A better understanding of the signaling pathways involved in the mechanism of action of berberine including fatty acid, insulin resistance, and glucose pathways was elucidated using metabolomic analysis

The mechanism of toxicity of aristolochic acid was elucidated and it involved direct cytotoxic effect and inhibition of the enzyme phospholipase A2 which renal function leading to renal failure

Poria cocos, a medicinal fungus used in TCM, induced positive changes in the fatty acid and sterol profile in an animal model for hyperlipidemia. Also, the signaling pathways affected by Poria cocos were identified using lipidomic analysis

The antioxidant capacity of 7S and its deglycosylated form D7S soy protein was evaluated. Both peptides showed antioxidant activity against free radicals and showed the effect on proliferation, oxidative status, and differentiation of $\mathrm{H}$-Caco- 2 cells

The Chinese formulae Liu Wei Di Huang Wan improved the restoration of the metabolic profile that was disturbed as a result of inflammation processes 
challenges are still of significant concern. Frequently, some of the components responsible for the therapeutic or toxic effect in TCM have not been fully characterized which hampers the analytical process $[102,108]$. Another limitation in quality control of herbal preparations is the lack of standards for the assessment of markers. However, alternative analytical methods such as quantitative analysis of multicomponent by a single marker (QAMS) have shown to be effective for the simultaneous analysis of multiple compounds [102].

In conclusion, the use of omic technologies has enormously contributed to improving the cost effectiveness, sensitivity, and reliability of analytical methods in the quality control process of TCM. Several analytical techniques are being introduced in quality control of herbal preparations at all stages of the production process. The need to have one optimized analytical procedure for one specific herbal preparation slows down the development of analytical protocols for TCM when compared to the analytical procedures of Western medicine. More extensive and oriented work is needed to overcome the issues encountered and to adopt the newest technological advances in TCM research. However, the introduction of existing technologies and the fast development of emerging omic tools provide a wide variety of analytical platforms and promising future to assist in the quality control of TCM.

\section{Omic Technologies in the Study of Potential Therapeutic Targets}

The study of therapeutic targets in TCM is a complex and challenging task. It requires the use of multiple methodologies combined to construct disease maps from different perspectives since the effect of TCMs is the final result of the effect on multiple targets. From the genomic point of view, about 30-40 thousand genes encode a larger number of proteins that represent potential drug targets for human diseases [14]. In this arena, omic technologies provide a wide variety of tools for the study of disease mechanisms and potential therapeutic targets.

As mentioned above, genomic technologies were the first methods to be applied in target discovery in combination with transcriptomics. Microarray analysis and mRNA expression profiles used to compare the normal state, disease related genes, or gene expression under treatment conditions have shown promising results for target validation. However, the gene expression profiles might not be directly correlated with the late functional biological state [14]. Therefore, limitations of genomic studies in target discovery and disease mechanisms should be addressed by combining the information collected with the use of other omic approaches such as proteomics.

The use of proteomic and metabolomic approaches applied to TCM research has increased since 2006. On the other hand, genomics and transcriptomics have not been widely used in TCM research when compared to proteomics and metabolomics as shown in observations made until 2012. Therefore, there is a clear need to explore genomic and transcriptomic technologies applied to TCM research [109].
Proteomic studies have contributed to the identification of potential drug targets not only by comparing the proteome profiles but also by using protein-drug or protein-protein interaction information [14]. In vitro and in vivo comparative proteomic studies using TCMs allow the identification of proteins that are present in the disease state when compared to the proteome of the normal state and those proteins can be considered as potential drug targets. After protein identification, the potential targets should be properly validated to ensure their involvement in the therapeutic effect of the compound or group of compounds studied. In TCM, identification of drug targets is essential for approval of TCM base drugs [110].

A close analysis of the methods used in proteomics for the study of the mechanism of disease has highlighted the pros and cons of such methods. For instance, a limitation being pointed out is the use of gel-based proteomics. Gel-based separation techniques can lead to partial peptide recovery from the gel which requires the use of several extraction steps to increase the peptide yield. However, the multistep methodologies are time-consuming compared to gel-free proteomic techniques. It has also been observed that the resolution of $1 \mathrm{D}$ gel systems is not good enough to analyze complex biological samples [111]. Furthermore, 2D gels have been a key method in comparative proteomic since their introduction in the mid-70s [61]. 2D gel technologies have partially overcome the problems encountered in the use of 1D gels; however, the poor resolution when high abundant proteins are present in the sample represents another issue in gel-based methods. In addition, gel-based technologies are time-consuming compared to other separation methods such as chromatographic techniques. In order to overcome the main problems observed in gel-based separation techniques, gel-free proteomics coupled with MS have shown to be a more efficient option in proteomic studies [111].

Proteomic studies can be combined with virtual screening technologies to predict binding profiles of the TCM components with potential target proteins and to build proteinprotein interaction maps to track the signaling pathways involved in the biological effects. Furthermore, the combined data from comparative proteomics, protein-drug, and protein-protein interaction provide useful information to support the process for candidate drug targets [14]. Important advances in MS techniques have been a key element in the study of the molecular targets of natural products [112]. Particularly, MS techniques namely MALDI-MS and ESIMS/MS have been widely applied in target discovery studies. In natural product research, MS methods coupled to separation techniques such as affinity chromatography, including small molecule-immobilized chromatography, biotinstreptavidin affinity chromatography, and photoaffinity labeling, have shown to be a powerful combination for target identification [112].

The study of posttranslational modifications (PTMs) in proteomics has enormously contributed to the understanding of molecular mechanisms in biological systems particularly for the identification of potential drug targets. The study of PTMs in biological systems is a challenging task due to the high diversity of PTMs. About 300 different types 
of PTMs have been identified using the most sophisticated analytical technologies [113]. New analytical platforms for the study of PTMs include PTM peptides enrichment steps after protein extraction and digestion that are followed by multidimensional analyses such as LC-MS/MS [113, 114]. Chromatographic-based methods are also being used in PTM studies including hydrophilic interaction chromatography (HILIC), chemical derivatization methods, enzymatic labeling approaches, and immunoaffinity chromatography methods for the study of glycopeptides [113]. Other chromatographic techniques used include the metal oxide affinity chromatography (MOAC) and immobilized metal ion affinity chromatography (IMAC) which are the most popular methods for the study of phosphoproteins $[113,115]$. Other types of PTMs such as ubiquitination are studied using antibodies for enrichment purposes combined with chromatographic techniques coupled with MS. MS/MS technologies combined with enrichment methods, such as acetyl-lysine antibodies, are used for the analysis of protein acetylation [113, 114]. Finally, protein methylation can be assessed by LC-MS/MS, SILAC-MS combined with enrichment techniques such as ion exchange chromatography, HILIC, and isoelectric focusing [113]. The information obtained from the study of PTMs using MS technology has contributed to the understanding of the signaling networks involved in disease development and drug activity representing one of the key approaches to generate information at a protein level for drug development purposes. Therefore, it is essential to apply the most advanced methods developed in TCM to contribute to a more efficient, sensitive, and time effective evaluation of TCMs.

Nowadays, proteomics technologies comprise a wide variety of high-throughput methods to study complex systems. A large amount of proteomic data generated can be analyzed using open source or commercial bioinformatics. Nevertheless, new bioanalytical approaches need to be developed to manage the enormous amount of proteomic data to improve the handling, analysis, and visualization of proteome information [62]. In TCM research, the use of the most recent analytical tools is growing slowly. On the other hand, the evolution of the omic technologies and the history of the implementation of omic technologies in TCM have shown that great efforts are being made to introduce those technologies in TCM research.

The comparison of the abnormalities in the metabolome to the normal stage provides an insight into the pathways affected at several disease stages, and it is known as comparative metabolomics [116]. For instance, in vitro, in vivo, and clinical studies have been carried out using MS and NMR technologies for the assessment of the metabolome in tumor diagnosis and evaluation of prognosis and to investigate the effect of the treatment [116]. Comparative omic approaches are useful tools that provide information about the disease state to identify the genes/proteins/metabolites involved in disease development compared to normal states [14]. A general overview of the application of omic technologies in differential or comparative studies indicated that coronary heart disease, chronic liver disease, hypertension, chronic kidney disease, hyperlipidemia and atherosclerosis, chronic stomach disease, and diabetes mellitus are the most common disorders studied in clinical TCM using omic technologies [109].

Furthermore, metabolomic studies have been shown to be helpful in the detection of response-to-treatment biomarkers which can be used for the development of new drugs [116]. Metabolic and inflammatory disorders are good examples in which metabolome profiling can assist in the identification of potential drug targets and disease biomarkers [14, 116]. The study of disease biomarkers provides information about diagnosis and disease development [117]. Recently, a proteomic technology that has been used in the identification of disease biomarkers is UPLC-MS ${ }^{\mathrm{E}}$. This approach involves the use of parallel alternating scans to generate ion information using low collision energy or to generate a full scan mass fragment, precursor ion, and neutral ion information by high collision energy. The information obtained by $\mathrm{MS}^{\mathrm{E}}$ has been shown to provide similar data to the data obtained by conventional MS/MS analysis. However, UPLC-MS ${ }^{\mathrm{E}}$ technology has the advantage of allowing the characterization of unknown biomarkers in an untargeted context [118]. For example, UPLC-MS ${ }^{\mathrm{E}}$ was used to study the metabonomic profile of chronic kidney disease induced by adenine excess and the protective effects of the TCM Poria cocos [119]. This metabonomic approach allowed the identification of disease biomarkers that can be also used to explain the mechanism of action of Poria cocos [119]. In other studies, the protective effect of rhubarb and ergone against chronic kidney disease was evaluated using UPLCQTOF/HDMS which provided valuable information about the pathogenesis of chronic kidney disease, identification of bioactive fractions, and the mechanism of action of both herbal mixtures [120, 121]. Another analytical tool is GC-MS which is considered a basic analytical tool in metabolomic studies together with NMR and LC-MS [122]. An example of the application of GC-MS in TCM research is a study in which a metabolomic profiling of depressed patients treated with Xiaoyaosan, a Chinese formula used for the treatment of depression and schizophrenia, was determined [122]. The metabolic profile obtained by GC-MS in this study allowed the monitoring of changes in the metabolome present in the urine of patients receiving Xiaoyasan treatment which provided more information about its regulatory effect of neurotransmitter metabolism and its beneficial effects on depression [122].

In high-throughput settings, metabolomics technologies are used not only for the identification of biomarkers but also for understanding the progression and the metabolome variation in the different disease stages which contributed to a better understanding of the pathology picture [116]. In addition, metabolomic profiling is a useful tool for the diagnosis and study of the pathological mechanisms. Nowadays, metabolomics approaches are being explored and introduced in the development of TCMs [14].

Methods such as NMR-based metabolite profiling, HPLC, GC-MS, GCxGC-TOF-MS, MALDI-TOF-MS, and CE-MS are metabolomic tools that can be used for the simultaneous analysis of 1000 compounds. Such technologies have shown to be fast, efficient, and sensitive for the detection 
of low abundance metabolites. In terms of bioinformatics analysis, great efforts are being made to improve the current tools in order to integrate the omic information and generate more reliable and complete bioinformatics tools. An example of such improved bioinformatic options is the Integrated Interactome System which comprises genes, proteins, metabolites, and drugs data [62]. Together with other bioinformatics tools such as the Human Metabolome Database, BioMagResBank, the Madison Consortium Database, MassBank, and the Golm Metabolome Database, metabolomics studies significantly contribute to picture detailed understanding of disease mechanisms and the identification of drug targets [116].

Metabolomics profiling can assist in the identification of early biomarkers of disease which is beneficial to detect early pathological stages [123]. Early disease biomarker detection is crucial for the implementation of prevention and therapeutic schemes in clinics. Therefore, sensitive detection methods to be developed and applied in TCM research are highly demanded. Great advances in the application of metabolomics techniques are taking place and the application of the most novel methods in TCM is being carried out. In addition to the omic data generated in TCM studies, pharmacological evaluation for target validation purposes in in vitro and in vivo models are needed to complement the information obtained by omic studies [14].

\section{Studying the Mechanism of Action of TCMs Using Omic Approaches}

Chinese formulations comprise a combination of several herbs. The active compounds in the formulations can act on specific targets and the biological activity is the result of combined effects. The final pharmacological action of the active compounds can be mutual accentuation, mutual enhancement, mutual suppression, mutual antagonism, or mutual incompatibility [6]. In order to develop drugs based on Chinese medicine, the mechanism of action and the identification of other cellular targets should be properly established to validate the pharmacological effect and determine possible side effects [110]. However, the multitarget actions of a large number of ingredients present in the formula represent a daunting resource-intensive challenge for TCM research, especially because most of the cellular targets and the mechanisms of action are unknown $[6,16,112,124]$.

There is an overlap in the methodologies for identification of disease mechanisms, biomarkers, drug targets, and the study of the mechanism of action of TCMs. Some of the technologies mentioned in the previous section are also used in the study of the molecular mechanisms in TCMs. Therefore, the most recent advances in omic technologies that have being applied in TCM research including some practical examples and technologies that need further exploration will be discussed.

Genomic approaches to the study of the mechanism of action of TCMs have been applied in the past years. A clear example of the use of recent sophisticated genomic technologies is the biclustering analysis of gene expression profiles using DNA microarray technology to identify gene expression variation. The data generated in the DNA microarray analysis is used to identify biologically relevant clusters for gene expression profiles resulting from chemical treatment to construct connectivity map (cMap) profiles. Consequently, the cMAP profiles are processed by biclustering analysis using a factor analysis for bicluster acquisition method. The data generated by the above-mentioned tools combining gene expression data, statistics, and bioinformatics contributed to the elucidation of the mechanism of action of TCMs and have shown potential for the analysis of complex herbal formulae [125].

A combination of technologies such as isoelectric focusing, SDS-PAGE, in-gel digestion, MALDI-TOF-MS, and realtime PCR have contributed to the identification of proteins involved in the mechanism of action of curcumin in in vitro models. Additionally, information about the signaling pathway in which the differential proteins act can provide with information about the function and signaling pathway involved in the mechanism of action [126]. In another study, a proteomic analysis using $2 \mathrm{D}$ gels, in-gel digestion, and MALDI/TOF/TOF coupled with bioinformatic analysis to obtain the protein-protein interaction network showed the identification of proteins and signaling pathways involved in the effect of curcumin on gastric cancer cells [127]. The studies mentioned above highlight the enormous amount of information and understanding of the mechanistic actions behind the effect of naturally derived compounds which supports the potential of omic studies in TCM research.

Another detailed study of the use of proteomics to determine the mechanism of action of TCMs was carried out by Lao et al., 2014. In this review, the authors summarize a number of studies based on proteomics in TCM research carried out in the past 10 years. In this review, it can be observed that proteomic technologies are being applied in the study of a wide variety of disorders in in vitro, in vivo, and in silico studies [128]. Proteomic technologies such as 2D gel electrophoresis, MALDI-TOF-MS combined peptide mass fingerprint, and the use of Mascot software are used to elucidate the mechanism of action of triterpenes in leukemia cells. The study showed the successful identification of proteins associated with the antitumor mechanism of TCM [129]. The mechanisms of action involved in the hepatoprotective effects of a TCM were investigated using a combination of 2D gel electrophoresis, MALDI-TOF/TOF-MS, and the construction of protein-protein interaction networks using bioinformatics tools (STRING). Identification of 7 target proteins was possible suggesting the potential of the proteomic strategy for the elucidation of the mechanism of action of TCMs [130]. Another recent study has implemented iTRAQbased quantitative technology for the identification of disease biomarkers and the mechanism of action of a Chinese medicine on a Parkinson's disease model. In this study, a detailed protein network map was constructed showing the molecular pathways involved in the neuroprotective effects of the medicinal plant studied and the identification of potential disease biomarkers [74].

When studying the mechanism of action of TCMs, the use of transcriptomic technologies applied to TCM is powerful tools due to the high sensitivity, accuracy, specificity, 
TABLE 3: Studies on TCM using omic technologies (P, proteomics; T, transcriptomics; M, metabolomics; PG; pharmacogenomics; G, genomics; L, lipidomics).

\begin{tabular}{|c|c|c|c|c|}
\hline Disease & TCM & $\begin{array}{l}\text { Omic approach: } \\
\text { method }\end{array}$ & Target or signaling pathway & Reference \\
\hline Parkinson's disease & Acanthopanax senticosus & P: iTRAQ & $\begin{array}{l}\text { Inhibition of the expression of Lewy } \\
\text { bodies; modulation of mitochondrial } \\
\text { energy metabolism, axonal transport, } \\
\text { and protein degradation; suppression } \\
\text { of endoplasmic reticulum stress and } \\
\text { apoptosis; maintenance of centrosome } \\
\text { integrity, iron, and calcium } \\
\text { homeostasis }\end{array}$ & [74] \\
\hline Anxiety & Radix Rehmanniae Preparata & $\begin{array}{c}\text { P: } 2 \text { DGE, } \\
\text { MALDI-TOF/MS }\end{array}$ & $\begin{array}{c}\text { Inhibition of MSG-induced } \\
\text { downregulation of } \beta \text {-synuclein, DJ-1, } \\
\text { peroxiredoxin-2, peroxiredoxin-6, } \\
\text { DDAH-1, and iron-sulfur proteins }\end{array}$ & {$[75]$} \\
\hline Cerebrovascular disease & $\begin{array}{l}\text { Tao Hong Si Wu decoction } \\
\text { (Semen Prunus, Flos } \\
\text { Carthami, Radix Rehmanniae } \\
\text { Preparata, Radix Angelicae } \\
\text { Sinensis, Rhizoma Ligustici } \\
\text { Chuanxiong, and } \\
\text { Radix Paeoniae Rubra) }\end{array}$ & $\begin{array}{c}\text { P: 2DGE, } \\
\text { MALDI-TOF-MS }\end{array}$ & $\begin{array}{c}\text { Regulation of Nrf2-mediated phase II } \\
\text { enzymes }\end{array}$ & {$[76]$} \\
\hline Chronic renal injury & Fu-Ling-Pi (Poria cocos) & $\begin{array}{c}\text { M: UPLC } \\
\text { Q-TOF/HSMS/MS }^{\mathrm{E}}\end{array}$ & $\begin{array}{l}\text { Regulation of adenine and amino acid } \\
\text { metabolism }\end{array}$ & [77] \\
\hline $\begin{array}{l}\text { Cardiovascular and } \\
\text { kidney disease, cancer }\end{array}$ & Venenum bufonis & M: NMR & $\begin{array}{l}\text { Cardiac acute toxicity by inhibition of } \\
\text { the } \mathrm{Na}+/ \mathrm{K}+\text {-ATPase pump, activation } \\
\text { of the mitochondrial apoptotic } \\
\text { pathway, increasing the levels of ROS, } \\
\text { disturbance of mitochondrial function, } \\
\text { and induction of apoptosis }\end{array}$ & {$[78]$} \\
\hline $\begin{array}{l}\text { Acute myocardial } \\
\text { ischemia }\end{array}$ & $\begin{array}{c}\text { Danqi Tongmai tablet (Salvia } \\
\text { miltiorrhiza and Panax } \\
\text { notoginseng) }\end{array}$ & $\begin{array}{l}\text { M: LC-LTQ-Orbitrap } \\
\text { MS }\end{array}$ & $\begin{array}{l}\text { Regulation of the tricarboxylic acid } \\
\text { cycle, amino, and nucleotide } \\
\text { metabolism }\end{array}$ & [79] \\
\hline Atherosclerosis & $\begin{array}{c}\text { Xin-Ke-Shu (Salvia miltiorrhiza, } \\
\text { Pueraria lobate, Panax } \\
\text { notoginseng, Crataegus } \\
\text { pinnatifida, Aucklandia lappa) }\end{array}$ & M: UPLC-Q-TOF MS & $\begin{array}{l}\text { Regulation of fatty acid, beta-oxidation } \\
\text { pathway, sphingolipid metabolism, } \\
\text { glycerophospholipid metabolism and } \\
\text { bile acid biosynthesis, proteolysis, } \\
\text { citrate cycle, lysine and glutathione, } \\
\text { glycerophospholipid, taurine, } \\
\text { hypotaurine, tryptophan, and } \\
\text { arachidonic acid }\end{array}$ & {$[80,81]$} \\
\hline $\begin{array}{l}\text { Hemolytic and aplastic } \\
\text { anemia }\end{array}$ & $\begin{array}{l}\text { Gui-Xiong (Angelicae Sinensis } \\
\text { Radix and Chuanxiong } \\
\text { Rhizoma) } \\
\end{array}$ & $\begin{array}{c}\text { M: } \\
\text { UHPLC-Q-TOF/MS }\end{array}$ & $\begin{array}{l}\text { Regulation of thiamine and } \\
\text { sphingolipid metabolism }\end{array}$ & {$[82]$} \\
\hline Rheumatoid arthritis & Huang-Lian-Jie-Du-Tang & M: LC-Q-TOF-MS & $\begin{array}{l}\text { Restoration to normal urinary levels of } \\
\text { citric acid, creatine, pantothenic acid, } \\
\text { carnitine, pantothenic acid, } \\
\text { phenylacetylglycine and plasma levels } \\
\text { of uric acid, L-histidine, and } \\
\text { L-phenylalanine }\end{array}$ & [83] \\
\hline $\begin{array}{l}\text { Systemic lupus } \\
\text { erythematosus }\end{array}$ & $\begin{array}{c}\text { Jieduquyuziyin (Radix } \\
\text { Rehmanniae, Carapax Trionycis, } \\
\text { Herba Artemisiae Annuae, } \\
\text { Rhizoma Cimicifugae foetidae, } \\
\text { Herba Hedyotidis, Radix } \\
\text { Paeoniae Rubra, Herba Centellae } \\
\text { Asiaticae, Semen Coicis, Fructus } \\
\text { Citri Sarcodactylis and Radix } \\
\text { Glycyrrhizae) }\end{array}$ & M: RRLC-Q-TOF/MS & $\begin{array}{l}\text { Regulation of unsaturated fatty acids } \\
\text { and phospholipid metabolic pathways }\end{array}$ & {$[84]$} \\
\hline
\end{tabular}


TABLE 3: Continued.

\begin{tabular}{|c|c|c|c|c|}
\hline Disease & TCM & $\begin{array}{l}\text { Omic approach: } \\
\text { method }\end{array}$ & Target or signaling pathway & Reference \\
\hline Gastric cancer & Salvia miltiorrhiza & $\begin{array}{c}\text { T and P: next } \\
\text { generation } \\
\text { sequencing-based } \\
\text { transcriptomics and } \\
\text { iTRAQ }\end{array}$ & $\begin{array}{l}\text { Inhibition of the metabolism of } \\
\text { glucose in gastric cancer cells and cell } \\
\text { growth }\end{array}$ & {$[85]$} \\
\hline Cancer & Cantharis vesicatoria & $\begin{array}{l}\text { PG: PCR array, } \\
\text { microarray-based } \\
\text { transcriptome-wide } \\
\text { mRNA expressions, } \\
\text { and COMPARE } \\
\text { analysis }\end{array}$ & $\begin{array}{c}\text { Induction of apoptosis by regulation of } \\
\text { tumor suppressors p53, p21, } \\
\text { mitochondrial Bax and Bcl-2 proteins, } \\
\text { JAK/STAT pathway, NF-KB, and } \\
\text { oxidative stress that leads to DNA } \\
\text { damage }\end{array}$ & {$[86]$} \\
\hline $\begin{array}{l}\text { Colon, ovarian, and lung } \\
\text { cancer }\end{array}$ & Artemisia anпua & $\begin{array}{l}\text { PG: microarray-based } \\
\text { transcriptome-wide } \\
\text { expression profiling } \\
\text { and compare analysis }\end{array}$ & $\begin{array}{l}\text { Regulation of TNF, tumor suppressor } \\
\text { p53, c-Myc, and Max-mediated } \\
\text { transcriptional control of gene } \\
\text { expression }\end{array}$ & [87] \\
\hline Ischemic stroke & $\begin{array}{l}\text { Bu-yang-Huan-wu decoction } \\
\text { (Astragalus membranaceus, } \\
\text { Angelica sinensis, Peonia } \\
\text { lactiflora, Ligusticum chanxiong, } \\
\text { Prunus persica, Carthamus } \\
\text { tinctorius and Pheretima } \\
\text { aspergillum) } \\
\end{array}$ & $\begin{array}{l}\text { G: affymetrix gene } \\
\text { chip array }\end{array}$ & $\begin{array}{l}\text { Downregulation of apoptosis, } \\
\text { inflammation, angiogenesis, and blood } \\
\text { coagulation genes; upregulation of } \\
\text { neurogenesis and nervous system } \\
\text { development genes }\end{array}$ & [88] \\
\hline Breast cancer & $\begin{array}{c}\text { Si-Wu-Tang extract (Paeoniae, } \\
\text { Angelicae, Chianxiong and } \\
\text { Rehmanniae) }\end{array}$ & $\begin{array}{l}\text { T and G: microarray } \\
\text { transcriptional } \\
\text { profiling }\end{array}$ & $\begin{array}{l}\text { Upregulation of GREB1, EGR3, PGR, } \\
\text { and inhibition of cell growth. }\end{array}$ & [89] \\
\hline $\begin{array}{l}\text { Lipopolysaccharide } \\
\text { induced diseases }\end{array}$ & $\begin{array}{c}\text { Pulsatillae decoction (Radix } \\
\text { Pulsatillae, Rhixoma Coptidis, } \\
\text { Cortex Phallodendri and Cortex } \\
\text { Fraxini) }\end{array}$ & G: affymetrix chip & $\begin{array}{c}\text { Reduction of } \\
\text { lipopolysaccharide-induced damage, } \\
\text { improvement of the physiological and } \\
\text { biochemical responses to overcome } \\
\text { the action of lipopolysaccharides }\end{array}$ & {$[90]$} \\
\hline Dyslipidemia & Review on different TCMs & $\begin{array}{c}\text { Several approaches } \\
\text { used such as } G, T \text {, and } \\
\text { M }\end{array}$ & Review on different TCMs & {$[91]$} \\
\hline Cancer & Panax ginseng & $\begin{array}{l}\text { Several approaches } \\
\text { used such as } G, P \text {, and } \\
\text { PG }\end{array}$ & $\begin{array}{c}\text { Stimulation of angiogenesis, } \\
\text { modulation of PI3k and AKT } \\
\text { pathways, regulation of cell adhesion, } \\
\text { migration, and cytoskeleton. Effect on } \\
\text { nuclear steroid hormone receptors }\end{array}$ & [92] \\
\hline
\end{tabular}

reproducibility, and high-throughput approach [131]. In addition, microarray technologies for the simultaneous monitoring of a large number of genes represent a very convenient platform for TCM studies. With the availability of wellestablished protocols for sample preparation, RNA isolation, and amplification, hybridization and data analysis have made this technology a valuable tool in TCM. Microarray technologies have been used to elucidate the mechanism of action of individual compounds or mixture of compounds in TCM studies. Taken together with databases of gene expression profiles of TCMs, construction of the drug-gene interaction signature provides information on the molecular pathways involved [131].

An example of the use of transcriptomics in the study of the mechanism of action of TCMs is the study carried out by Liu et al., 2013. In this study, differential microarray gene expression analysis in an in vitro platform combined with pharmacological studies for validation purposes to elucidate the mechanism of action of the TCM studied. The data generated were analyzed using the software ArrayTrack, CLUSTER, and TREEVIEW. The approach used improved the understanding of the mechanism of action and the potential use of the TCM in cancer treatment [89]. Additional examples of studies carried out on TCMs using omic approaches to elucidate the mechanism of action are shown in Table 3.

The use of metabolomics technologies provides a deeper insight into the metabolic changes accompanied by TCM treatment which enables biomarker identification and elucidation of mode-of-action. Danqi Tongmai tablet was shown to have a protective effect against acute myocardial infarction. Comparison of metabolomic profile of Danqi Tongmai tablet treated and untreated rats were subjected to pathway analysis to identify the pathways modified in Danqi Tongmai tablet 
treated rats. Briefly, the knowledge from Kyoto Encyclopedia of Genes and Genomes (KEGG) was utilized to identify deregulated pathways. A more detailed statistical test of pathway enrichment and comparison of pathway topology were conducted in MetaboAnalyst [79]. The study demonstrated a systems-level analysis of metabolic profile for understanding TCM effector mechanism.

Although omic technologies have being applied in the study of the molecular mechanism by which TCMs exhibit their biological effects, more exploration is needed to take full advantage of the wide range of technologies currently available.

\section{Conclusions}

Omic technologies have shown enormous potential in the modernization of TCM. Gradually, omic approaches have being introduced in every stage of the development process to generate high-quality TCMs. The complexity of TCM in terms of composition and multitarget effects has being addressed by omic approaches. However, further study and optimization of the current methodologies are needed to successfully overcome the most common bottlenecks in TCM research. The high chemical and pharmacological diversity found in TMCs requires the development of a suitable set of omic technologies established in a strategic manner and adapted to every specific compound, a group of compounds, or TCM extracts. Because each plant, formulae, extract, or group of compounds has different physicochemical nature and contains different active and toxic compounds as well as analytical and active biomarkers, each case requires specific analytical approaches and methodologies that cannot be applied to another plant, formulae, extract, or group of compounds. The wide variety of technologies available needs to be further explored and the feasibility of any particular omic technology or the combination of multiomic approaches needs to be studied in detail. Therefore, validation of the strategic omic approaches applied is needed to support their introduction in guidelines and to allow the development of standard operation procedures to facilitate reproducibility, harmonization, and standardization of the protocols used in the development of TCMs. Emerging novel and sophisticated omic technologies will require a continuous study and application in TCM research. Finally, the future picture of the use of omic technologies is a promising tool and arena for further improvement in the modernization of TCM.

\section{Competing Interests}

Hereby, the authors declare that there is no conflict of interests regarding the publication of the present review paper.

\section{References}

[1] A. L. Harvey, R. Edrada-Ebel, and R. J. Quinn, "The re-emergence of natural products for drug discovery in the genomics era," Nature Reviews Drug Discovery, vol. 14, no. 2, pp. 111-129, 2015.
[2] B. Patwardhan, D. Warude, P. Pushpangadan, and N. Bhatt, "Ayurveda and traditional Chinese medicine: a comparative overview," Evidence-Based Complementary and Alternative Medicine, vol. 2, no. 4, pp. 465-473, 2005.

[3] D. J. Newman and G. M. Cragg, "Natural products as sources of new drugs over the 30 years from 1981 to 2010," Journal of Natural Products, vol. 75, no. 3, pp. 311-335, 2012.

[4] D. J. Newman and G. M. Cragg, "Natural products as sources of new drugs over the last 25 years," Journal of Natural Products, vol. 70, no. 3, pp. 461-477, 2007.

[5] T.-P. Fan, G. Deal, H.-L. Koo et al., "Future development of global regulations of Chinese herbal products," Journal of Ethnopharmacology, vol. 140, no. 3, pp. 568-586, 2012.

[6] R. Yuan and Y. Lin, "Traditional Chinese medicine: an approach to scientific proof and clinical validation," Pharmacology and Therapeutics, vol. 86, no. 2, pp. 191-198, 2000.

[7] WHO, WHO Traditional Medicine Strategy 2014-2023, World Health Organization, Genève, Switzerland, 2013.

[8] W.-Y. Jiang, "Therapeutic wisdom in traditional Chinese medicine: a perspective from modern science," Trends in Pharmacological Sciences, vol. 26, no. 11, pp. 558-563, 2005.

[9] M. V. Olson, “The human genome project: a player's perspective," Journal of Molecular Biology, vol. 319, no. 4, pp. 931-942, 2002.

[10] S. K. Chanda and J. S. Caldwell, "Fulfilling the promise: drug discovery in the post-genomic era," Drug Discovery Today, vol. 8, no. 4, pp. 168-174, 2003.

[11] F. S. Collins, E. D. Green, A. E. Guttmacher, and M. S. Guyer, "A vision for the future of genomics research," Nature, vol. 422, no. 6934, pp. 835-847, 2003.

[12] O. Pelkonen, M. Pasanen, J. C. Lindon et al., "Omics and its potential impact on $\mathrm{R} \& \mathrm{D}$ and regulation of complex herbal products," Journal of Ethnopharmacology, vol. 140, no. 3, pp. 587-593, 2012.

[13] T. Reiss, "Drug discovery of the future: the implications of the human genome project," Trends in Biotechnology, vol. 19, no. 12, pp. 496-499, 2001.

[14] S.-K. Yan, R.-H. Liu, H.-Z. Jin et al., “'Omics' in pharmaceutical research: overview, applications, challenges, and future perspectives," Chinese Journal of Natural Medicines, vol. 13, no. 1, pp. 321, 2015.

[15] X. Wang, A. Zhang, H. Sun, and P. Wang, "Systems biology technologies enable personalized traditional chinese medicine: a systematic review," American Journal of Chinese Medicine, vol. 40, no. 6, pp. 1109-1122, 2012.

[16] A. Buriani, M. L. Garcia-Bermejo, E. Bosisio et al., "Omic techniques in systems biology approaches to traditional Chinese medicine research: present and future," Journal of Ethnopharmacology, vol. 140, no. 3, pp. 535-544, 2012.

[17] Z.-Y. Su, L. Shu, J. H. Lee et al., "Perspective on Nrf2, epigenomics and cancer stem cells in cancer chemoprevention using dietary phytochemicals and traditional Chinese medicines," Progress in Chemistry, vol. 25, no. 9, pp. 1526-1543, 2013.

[18] H. Li, M. Zhou, A. Zhao, and W. Jia, "Traditional Chinese medicine: balancing the gut ecosystem," Phytotherapy Research, vol. 23, no. 9, pp. 1332-1335, 2009.

[19] C. Gao, D. Weisman, J. Lan, N. Gou, and A. Z. Gu, “Toxicity mechanisms identification via gene set enrichment analysis of time-series toxicogenomics data: impact of time and concentration," Environmental Science and Technology, vol. 49, no. 7, pp. 4618-4626, 2015. 
[20] M. D. Waters and J. M. Fostel, "Toxicogenomics and systems toxicology: aims and prospects," Nature Reviews Genetics, vol. 5, no. 12, pp. 936-948, 2004.

[21] A. K. Daly, "Pharmacogenomics of adverse drug reactions," Genome Medicine, vol. 5, article 5, 2013.

[22] P. Shahabi and M.-P. Dubé, "Cardiovascular pharmacogenomics; state of current knowledge and implementation in practice," International Journal of Cardiology, vol. 184, no. 1, pp. 772-795, 2015.

[23] Y. J. Kang, "Herbogenomics: from traditional Chinese medicine to novel therapeutics," Experimental Biology and Medicine, vol. 233, no. 9, pp. 1059-1065, 2008.

[24] K. L. Denzler, R. Waters, B. L. Jacobs, Y. Rochon, and J. O. Langland, "Regulation of inflammatory gene expression in PBMCs by immunostimulatory botanicals," PloS one, vol. 5, no. 9, Article ID e12561, 2010.

[25] R. M. Twyman, Principles of Proteomics, Garland Science, New York, NY, USA; Taylor Francis Group LLC, Boca Raton, Fla, USA, 2nd edition, 2014.

[26] P. Cutler and H. Voshol, "Proteomics in pharmaceutical research and development," Proteomics-Clinical Applications, vol. 9, no. 7-8, pp. 643-650, 2015.

[27] I. M. Cristea, S. J. Gaskell, and A. D. Whetton, "Proteomics techniques and their application to hematology," Blood, vol. 103, no. 10, pp. 3624-3634, 2004.

[28] P. Li, L.-P. Yang, and Y.-W. Gong, "Application of systems biology technology in research of traditional Chinese medicine," Journal of Traditional Chinese Medicine, vol. 29, no. 2, pp. 153157, 2009.

[29] O. Pagel, S. Loroch, A. Sickmann, and R. P. Zahedi, "Current strategies and findings in clinically relevant post-translational modification-specific proteomics," Expert Review of Proteomics, vol. 12, no. 3, pp. 235-253, 2015.

[30] R. B. Van Breemen, H. H. S. Fong, and N. R. Farnsworth, "Ensuring the safety of botanical dietary supplements," American Journal of Clinical Nutrition, vol. 87, no. 2, pp. 509S-5013S, 2008.

[31] M. Bantscheff and G. Drewes, "Chemoproteomic approaches to drug target identification and drug profiling," Bioorganic and Medicinal Chemistry, vol. 20, no. 6, pp. 1973-1978, 2012.

[32] A. Bulman, M. Neagu, and C. Constantin, "Immunomics in skin cancer-improvement in diagnosis, prognosis and therapy monitoring," Current Proteomics, vol. 10, no. 3, pp. 202-217, 2013.

[33] H.-D. Ma, Y.-R. Deng, Z. Tian, and Z.-X. Lian, "Traditional Chinese medicine and immune regulation," Clinical Reviews in Allergy and Immunology, vol. 44, no. 3, pp. 229-241, 2013.

[34] H. Ohashi, M. Hasegawa, K. Wakimoto, and E. MiyamotoSato, "Next-generation technologies for multiomics approaches including interactome sequencing," BioMed Research International, vol. 2015, Article ID 104209, 9 pages, 2015.

[35] G. Ulrich-Merzenich, H. Zeitler, D. Jobst, D. Panek, H. Vetter, and H. Wagner, "Application of the "-Omic-" technologies in phytomedicine," Phytomedicine, vol. 14, no. 1, pp. 70-82, 2007.

[36] R. Kaddurah-Daouk and R. M. Weinshilboum, "Pharmacometabolomics: implications for clinical pharmacology and systems pharmacology," Clinical Pharmacology and Therapeutics, vol. 95, no. 2, pp. 154-167, 2014.

[37] M. Bouhifd, T. Hartung, H. T. Hogberg, A. Kleensang, and L. Zhao, "Review: toxicometabolomics," Journal of Applied Toxicology, vol. 33, no. 12, pp. 1365-1383, 2013.
[38] X. Zhang, H. Wu, P. Liao, X. Li, J. Ni, and F. Pei, "NMR-based metabonomic study on the subacute toxicity of aristolochic acid in rats," Food and Chemical Toxicology, vol. 44, no. 7, pp. 10061014, 2006.

[39] Y. Ni, M. Su, Y. Qiu et al., "Metabolic profiling using combined GC-MS and LC-MS provides a systems understanding of aristolochic acid-induced nephrotoxicity in rat," FEBS Letters, vol. 581, no. 4, pp. 707-711, 2007.

[40] W. Chan, K.-C. Lee, N. Liu, R. N. S. Wong, H. Liu, and Z. Cai, "Liquid chromatography/mass spectrometry for metabonomics investigation of the biochemical effects induced by aristolochic acid in rats: the use of information-dependent acquisition for biomarker identification," Rapid Communications in Mass Spectrometry, vol. 22, no. 6, pp. 873-880, 2008.

[41] X. Liu, Y. Xiao, H.-C. Gao, J. Ren, and D.-H. Lin, "Metabonomic study of aristolochic acid I-induced acute renal toxicity urine at female and male C57BL/6J Mice based on H-1 NMR," Gaodeng Xuexiao Huaxue Xuebao/Chemical Journal of Chinese Universities, vol. 31, no. 5, pp. 927-932, 2010.

[42] P. Guo, J. Wang, G. Dong et al., "NMR-based metabolomics approach to study the chronic toxicity of crude ricin from castor bean kernels on rats," Molecular BioSystems, vol. 10, no. 9, pp. 2426-2440, 2014.

[43] J. Aa, F. Shao, G. Wang et al., "Gas chromatography timeof-flight mass spectrometry based metabolomic approach to evaluating toxicity of triptolide," Metabolomics, vol. 7, no. 2, pp. 217-225, 2011.

[44] C. C. Teo, W. P. K. Chong, E. Tan, N. B. Basri, Z. J. Low, and Y. S. Ho, "Advances in sample preparation and analytical techniques for lipidomics study of clinical samples," TrAC-Trends in Analytical Chemistry, vol. 66, pp. 1-18, 2015.

[45] G. Astarita and M. Ollero, "Lipidomics: an evolving discipline in molecular sciences," International Journal of Molecular Sciences, vol. 16, no. 4, pp. 7748-7752, 2015.

[46] M. D. Del Castillo, N. Martinez-Saez, M. Amigo-Benavent, and J. M. Silvan, "Phytochemomics and other omics for permitting health claims made on foods," Food Research International, vol. 54, no. 1, pp. 1237-1249, 2013.

[47] X. Wang, A. Zhang, and H. Sun, "Future perspectives of Chinese medical formulae: chinmedomics as an effector," OMICS A Journal of Integrative Biology, vol. 16, no. 7-8, pp. 414-421, 2012.

[48] A.-H. Zhang, H. Sun, G.-L. Yan, P. Wang, Y. Han, and X.-J. Wang, "Chinmedomics: a new strategy for research of traditional Chinese medicine," Zhongguo Zhong Yao Za Zhi, vol. 40, no. 4, pp. 569-576, 2015.

[49] X. Wang, A. Zhang, and H. Sun, Eds., Chinmedomics: The Integration of Serum Pharmacochemistry and Metabolomics to Elucidate the Scientific Value of Traditional Chinese Medicine, Mica Haley, 1st edition, 2015.

[50] Y. Ogra, "Development of metallomics research on environmental toxicology," Yakugaku Zasshi journal of the Pharmaceutical Society of Japan, vol. 135, no. 2, pp. 307-314, 2015.

[51] I. Baxter, "Should we treat the ionome as a combination of individual elements, or should we be deriving novel combined traits?" Journal of Experimental Botany, vol. 66, no. 8, pp. 21272131, 2015.

[52] D. E. Salt, I. Baxter, and B. Lahner, "Ionomics and the study of the plant ionome," Annual Review of Plant Biology, vol. 59, pp. 709-733, 2008.

[53] D. Wu, Q. Shen, S. Cai, Z.-H. Chen, F. Dai, and G. Zhang, "Ionomic responses and correlations between elements and 
metabolites under salt stress in wild and cultivated barley," Plant and Cell Physiology, vol. 54, no. 12, pp. 1976-1988, 2013.

[54] R. Hoehndorf, P. N. Schofield, and G. V. Gkoutos, "Analysis of the human diseasome using phenotype similarity between common, genetic, and infectious diseases," Scientific Reports, vol. 5, Article ID 10888, 2015.

[55] A. A. Monte, C. Brocker, D. W. Nebert, F. J. Gonzalez, D. C. Thompson, and V. Vasiliou, "Improved drug therapy: triangulating phenomics with genomics and metabolomics," Human Genomics, vol. 8, article 16, 2014.

[56] G. Valet, "Cytomics: an entry to biomedical cell systems biology," Cytometry Part A, vol. 63, no. 2, pp. 67-68, 2005.

[57] H. Lee, "Genetically engineered mouse models for drug development and preclinical trials," Biomolecules and Therapeutics, vol. 22, no. 4, pp. 267-274, 2014.

[58] Y. Baba, "Development of novel biomedicine based on genome science," European Journal of Pharmaceutical Sciences, vol. 13, no. 1, pp. 3-4, 2001.

[59] G.-J. B. van Ommen, "The Human Genome Project and the future of diagnostics, treatment and prevention," Journal of Inherited Metabolic Disease, vol. 25, no. 3, pp. 183-188, 2002.

[60] J.-F. Wang and D.-Q. Wei, "Role of structural bioinformatics and traditional Chinese medicine databases in pharmacogenomics," Pharmacogenomics, vol. 10, no. 8, pp. 1213-1215, 2009.

[61] W. C.-S. Cho, "Application of proteomics in Chinese medicine research," American Journal of Chinese Medicine, vol. 35, no. 6, pp. 911-922, 2007.

[62] C. M. Carnielli, F. V. Winck, and A. F. P. Leme, "Functional annotation and biological interpretation of proteomics data," Biochimica et Biophysica Acta-Proteins and Proteomics, vol. 1854, no. 1, pp. 46-54, 2015.

[63] Q.-R. Li, Z.-B. Ning, X.-L. Yang, J.-R. Wu, and R. Zeng, "Complementary workflow for global phosphoproteome analysis," Electrophoresis, vol. 33, no. 22, pp. 3291-3298, 2012.

[64] J. Cieśla, T. Fraczyk, and W. Rode, "Phosphorylation of basic amino acid residues in proteins: important but easily missed," Acta Biochimica Polonica, vol. 58, no. 2, pp. 137-148, 2011.

[65] A. Taylor, M. P. Day, S. Hill, and J. Marshall, "Atomic spectrometry update: review of advances in the analysis of clinical and biological materials, foods and beverages," Journal of Analytical Atomic Spectrometry, vol. 29, no. 3, pp. 386-426, 2014.

[66] R. Djingova, V. Mihaylova, V. Lyubomirova, and D. L. Tsalev, "Multielement analytical spectroscopy in plant ionomics research," Applied Spectroscopy Reviews, vol. 48, no. 5, pp. 384424, 2013.

[67] T. M. Kalyankar, S. J. Wadher, S. S. Dange, M. S. Attar, and A. M. Pattewar, "Analysis of herbal drugs: a review," Asian Journal of Pharmaceutical Analysis and Medicinal Chemistry, vol. 1, article 12, 2014.

[68] Z. Qu, J. Cui, Y. Harata-Lee et al., "Identification of candidate anti-cancer molecular mechanisms of compound kushen injection using functional genomics," Oncotarget, 2016.

[69] H.-M. Cheng, C.-C. Li, C. Y.-C. Chen et al., "Application of bioactivity database of Chinese herbal medicine on the therapeutic prediction, drug development, and safety evaluation," Journal of Ethnopharmacology, vol. 132, no. 2, pp. 429-437, 2010.

[70] Y. Gu, Y. Zhang, X. Shi et al., "Effect of traditional Chinese medicine berberine on type 2 diabetes based on comprehensive metabonomics," Talanta, vol. 81, no. 3, pp. 766-772, 2010.

[71] H. Miao, Y.-H. Zhao, N. D. Vaziri et al., "Lipidomics biomarkers of diet-induced hyperlipidemia and its treatment with poria cocos," Journal of Agricultural and Food Chemistry, vol. 64, no. 4, pp. 969-979, 2016.

[72] M. Amigo-Benavent, A. Clemente, S. Caira, P. Stiuso, P. Ferranti, and M. D. Del Castillo, "Use of phytochemomics to evaluate the bioavailability and bioactivity of antioxidant peptides of soybean $\beta$-conglycinin," Electrophoresis, vol. 35, no. 11, pp. 15821589, 2014.

[73] X. Wang, H. Lv, H. Sun et al., "Metabolic urinary profiling of alcohol hepatotoxicity and intervention effects of Yin Chen Hao Tang in rats using ultra-performance liquid chromatography/electrospray ionization quadruple time-of-flight mass spectrometry," Journal of Pharmaceutical and Biomedical Analysis, vol. 48, no. 4, pp. 1161-1168, 2008.

[74] X.-Z. Li, S.-N. Zhang, K.-X. Wang, S.-M. Liu, and F. Lu, "ITRAQ-based quantitative proteomics study on the neuroprotective effects of extract of Acanthopanax senticosus harm on SH-SY5Y cells overexpressing A53T mutant $\alpha$-synuclein," Neurochemistry International, vol. 72, no. 1, pp. 37-47, 2014.

[75] Y. Cui, C. Rong, J. Wang et al., "Mechanism-based anti-anxiety effects of polysaccharides extracted from Shudihuang (radix rehmanniae Preparata) by two-dimensional electrophoresis analysis in rat hippocampus proteins," Journal of Traditional Chinese Medicine, vol. 33, no. 4, pp. 524-530, 2013.

[76] H.-Y. Qi, L. Li, J. Yu et al., "Proteomic identification of Nrf2mediated phase II enzymes critical for protection of Tao Hong $\mathrm{Si} \mathrm{Wu}$ decoction against oxygen glucose deprivation injury in PC12 cells," Evidence-based Complementary and Alternative Medicine, vol. 2014, Article ID 945814, 11 pages, 2014.

[77] Y.-Y. Zhao, H.-T. Li, Y.-L. Feng, X. Bai, and R.-C. Lin, “Urinary metabonomic study of the surface layer of Poria cocos as an effective treatment for chronic renal injury in rats," Journal of Ethnopharmacology, vol. 148, no. 2, pp. 403-410, 2013.

[78] G. Dong, D. Wei, J. Wang et al., "Study of the cardiotoxicity of venenum bufonis in rats using an $1 \mathrm{H}$ NMR-based metabolomics approach," PLoS ONE, vol. 10, no. 3, Article ID e0119515, 2015.

[79] B. Yan, Y. Deng, J. Hou et al., "UHPLC-LTQ-Orbitrap MS combined with spike-in method for plasma metabonomics analysis of acute myocardial ischemia rats and pretreatment effect of Danqi Tongmai tablet," Molecular BioSystems, vol. 11, no. 2, pp. 486-496, 2015.

[80] Y.-T. Liu, J.-B. Peng, H.-M. Jia et al., "UPLC-Q/TOF MS standardized Chinese formula Xin-Ke-Shu for the treatment of atherosclerosis in a rabbit model," Phytomedicine, vol. 21, no. 11, pp. 1364-1372, 2014.

[81] Y.-T. Liu, J.-B. Peng, H.-M. Jia, H.-W. Zhang, G. Ding, and Z.M. Zou, "Urinary metabonomic evaluation of the therapeutic effect of traditional Chinese medicine Xin-Ke-Shu against atherosclerosis rabbits using UPLC-Q/TOF MS," Chemometrics and Intelligent Laboratory Systems, vol. 136, pp. 104-114, 2014.

[82] W. Li, Y. Tang, J. Guo et al., "Comparative metabolomics analysis on hematopoietic functions of herb pair Gui-Xiong by ultra-high-performance liquid chromatography coupled to quadrupole time-of-flight mass spectrometry and pattern recognition approach," Journal of Chromatography A, vol. 1346, pp. 49-56, 2014.

[83] H. Zhang, P. Fu, B. Ke et al., "Metabolomic analysis of biochemical changes in the plasma and urine of collagen-induced arthritis in rats after treatment with Huang-Lian-Jie-Du-Tang," Journal of Ethnopharmacology, vol. 154, no. 1, pp. 55-64, 2014.

[84] X. Ding, J. Hu, C. Wen, Z. Ding, L. Yao, and Y. Fan, "Rapid resolution liquid chromatography coupled with quadrupole timeof-flight mass spectrometry-based metabolomics approach to 
study the effects of jieduquyuziyin prescription on systemic lupus erythematosus," PLOS ONE, vol. 9, no. 2, Article ID e88223, 2014.

[85] L.-L. Lin, C.-R. Hsia, C.-L. Hsu, H.-C. Huang, and H.-F. Juan, "Integrating transcriptomics and proteomics to show that tanshinone IIA suppresses cell growth by blocking glucose metabolism in gastric cancer cells," BMC Genomics, vol. 16, article 41, 2015.

[86] O. Kadioglu, N. S. Kermani, G. Kelter et al., "Pharmacogenomics of cantharidin in tumor cells," Biochemical Pharmacology, vol. 87, no. 3, pp. 399-409, 2014.

[87] S. Sertel, T. Eichhorn, C. H. Simon, P. K. Plinkert, S. W. Johnson, and T. Efferth, "Pharmacogenomic identification of c-Myc/ Max-regulated genes associated with cytotoxicity of artesunate towards human colon, ovarian and lung cancer cell lines," Molecules, vol. 15, no. 4, pp. 2886-2910, 2010.

[88] H.-W. Wang, K.-T. Liou, Y.-H. Wang et al., "Deciphering the neuroprotective mechanisms of Bu-yang Huan-wu decoction by an integrative neurofunctional and genomic approach in ischemic stroke mice," Journal of Ethnopharmacology, vol. 138, no. 1, pp. 22-33, 2011.

[89] M. Liu, J. Fan, S. Wang et al., "Transcriptional profiling of Chinese medicinal formula Si-Wu-Tang on breast cancer cells reveals phytoestrogenic activity," BMC Complementary and Alternative Medicine, vol. 13, article 11, 2013.

[90] Y. Hu, X. Chen, H. Lin, Y. Hu, and X. Mu, "Study on the antiendotoxin action of Pulsatillae Decoction using an Affymetrix rat genome array," Cellular Immunology, vol. 257, no. 1-2, pp. 32-37, 2009.

[91] W. J. Bei, J. Guo, H. Y. Wu, and Y. Cao, "Lipid-regulating effect of traditional chinese medicine: mechanisms of actions," Evidence-Based Complementary and Alternative Medicine, vol. 2012, Article ID 970635, 10 pages, 2012.

[92] P. Y. K. Yue, N. K. Mak, Y. K. Cheng et al., "Pharmacogenomics and the Yin/Yang actions of ginseng: anti-tumor, angiomodulating and steroid-like activities of ginsenosides," Chinese Medicine, vol. 2, article 6, 2007.

[93] S. P. Li, J. Zhao, and B. Yang, "Strategies for quality control of Chinese medicines," Journal of Pharmaceutical and Biomedical Analysis, vol. 55, no. 4, pp. 802-809, 2011.

[94] S. A. Jordan, D. G. Cunningham, and R. J. Marles, "Assessment of herbal medicinal products: challenges, and opportunities to increase the knowledge base for safety assessment," Toxicology and Applied Pharmacology, vol. 243, no. 2, pp. 198-216, 2010.

[95] N. Sahoo, P. Manchikanti, and S. Dey, "Herbal drugs: standards and regulation," Fitoterapia, vol. 81, no. 6, pp. 462-471, 2010.

[96] P. Claeson, "Requirements on efficacy of herbal medicinal products," Journal of Ethnopharmacology, vol. 158, pp. 463-466, 2014.

[97] Y. Jiang, B. David, P. Tu, and Y. Barbin, "Recent analytical approaches in quality control of traditional Chinese medicines-a review," Analytica Chimica Acta, vol. 657, no. 1, pp. 9-18, 2010.

[98] B. H. Kroes, "The legal framework governing the quality of (traditional) herbal medicinal products in the European Union," Journal of Ethnopharmacology, vol. 158, pp. 449-453, 2014.

[99] F. Van Der Kooy, F. Maltese, H. C. Young, K. K. Hye, and R. Verpoorte, "Quality control of herbal material and phytopharmaceuticals with MS and NMR based metabolic fingerprinting," Planta Medica, vol. 75, no. 7, pp. 763-775, 2009.
[100] Y. Liu, J. Liu, P. Yin, M. Gao, C. Deng, and X. Zhang, "High throughput identification of components from traditional Chinese medicine herbs by utilizing graphene or graphene oxide as MALDI-TOF-MS matrix," Journal of mass spectrometry : JMS, vol. 46, no. 8, pp. 804-815, 2011.

[101] D. Steinmann and M. Ganzera, "Recent advances on HPLC/MS in medicinal plant analysis," Journal of Pharmaceutical and Biomedical Analysis, vol. 55, no. 4, pp. 744-757, 2011.

[102] X.-Y. Song, Y.-D. Li, Y.-P. Shi, L. Jin, and J. Chen, "Quality control of traditional Chinese medicines: a review," Chinese Journal of Natural Medicines, vol. 11, no. 6, pp. 596-607, 2013.

[103] S. Chen, J. Song, C. Sun et al., "Herbal genomics: examining the biology of traditional medicines," Science, vol. 347, no. 6219, pp. S27-S29, 2015.

[104] M. Jiang, Y. Jiao, Y. Wang et al., "Quantitative profiling of polar metabolites in herbal medicine injections for multivariate statistical evaluation based on independence principal component analysis," PLoS ONE, vol. 9, no. 8, Article ID e105412, 2014.

[105] P. H. Chan, W. L. Zhang, C. Y. Cheung, K. W. K. Tsim, and H. Lam, "Quality control of Danggui Buxue Tang, a traditional Chinese medicine decoction, by ${ }^{1} \mathrm{H}-\mathrm{NMR}$ metabolic profiling," Evidence-based Complementary and Alternative Medicine, vol. 2014, Article ID 567893, 8 pages, 2014.

[106] Y. Wang, S. He, X. Cheng, Y. Lu, Y. Zou, and Q. Zhang, "UPLC-Q-TOF-MS/MS fingerprinting of Traditional Chinese Formula SiJunZiTangnZiTang," Journal of Pharmaceutical and Biomedical Analysis, vol. 80, pp. 24-33, 2013.

[107] F. Firenzuoli and L. Gori, "Herbal medicine today: clinical and research issues," Evidence-Based Complementary and Alternative Medicine, vol. 4, no. S1, pp. 37-40, 2007.

[108] J. Wang, R. van der Heijden, S. Spruit et al., "Quality and safety of Chinese herbal medicines guided by a systems biology perspective," Journal of Ethnopharmacology, vol. 126, no. 1, pp. 31-41, 2009.

[109] Y.-N. Song, G.-B. Zhang, Y.-Y. Zhang, and S.-B. Su, "Clinical applications of omics technologies on Zheng differentiation research in traditional Chinese medicine," Evidence-based Complementary and Alternative Medicine, vol. 2013, Article ID 989618, 11 pages, 2013.

[110] T. Bottcher, M. Pitscheider, and S. A. Sieber, "Natural products and their biological targets: proteomic and metabolomic labeling strategies," Angew Chemie, vol. 49, no. 15, pp. 2680-2698, 2010.

[111] S. Camerini and P. Mauri, "The role of protein and peptide separation before mass spectrometry analysis in clinical proteomics," Journal of Chromatography A, vol. 1381, pp. 1-12, 2015.

[112] K.-W. Cheng, C.-C. Wong, M. Wang, Q.-Y. He, and F. Chen, "Identification and characterization of molecular targets of natural products by mass spectrometry," Mass Spectrometry Reviews, vol. 29, no. 1, pp. 126-155, 2010.

[113] J. Huang, F. Wang, M. Ye, and H. Zou, "Enrichment and separation techniques for large-scale proteomics analysis of the protein post-translational modifications," Journal of Chromatography A, vol. 1372, pp. 1-17, 2014.

[114] L. Beltran and P. R. Cutillas, "Advances in phosphopeptide enrichment techniques for phosphoproteomics," Amino Acids, vol. 43, no. 3, pp. 1009-1024, 2012.

[115] J. A. J. Jaros, P. C. Guest, H. Ramoune et al., "Clinical use of phosphorylated proteins in blood serum analysed by immobilised metal ion affinity chromatography and mass spectrometry," Journal of Proteomics, vol. 76, pp. 36-42, 2012. 
[116] L.-F. Shyur and N.-S. Yang, "Metabolomics for phytomedicine research and drug development," Current Opinion in Chemical Biology, vol. 12, no. 1, pp. 66-71, 2008.

[117] J. Wang, X. Peng, W. Peng, and F.-X. Wu, "Dynamic protein interaction network construction and applications," Proteomics, vol. 14, no. 4-5, pp. 338-352, 2014.

[118] Y.-Y. Zhao and R.-C. Lin, "UPLC-MS ${ }^{E}$ application in disease biomarker discovery: the discoveries in proteomics to metabolomics," Chemico-Biological Interactions, vol. 215, pp. 716, 2014.

[119] Y.-Y. Zhao, Y.-L. Feng, X. Bai, X.-J. Tan, R.-C. Lin, and Q. Mei, "Ultra performance liquid chromatography-based metabonomic study of therapeutic effect of the surface layer of poria cocos on adenine-induced chronic kidney disease provides new insight into anti-fibrosis mechanism," PLoS ONE, vol. 8, no. 3, Article ID e59617, 2013.

[120] Y.-Y. Zhao, H. Chen, T. Tian et al., "A pharmaco-metabonomic study on chronic kidney disease and therapeutic effect of Ergone by UPLC-QTOF/HDMS," PLOS ONE, vol. 9, no. 12, Article ID el15467, 2014.

[121] Z.-H. Zhang, F. Wei, N. D. Vaziri et al., "Metabolomics insights into chronic kidney disease and modulatory effect of rhubarb against tubulointerstitial fibrosis," Scientific Reports, vol. 5, article no. 14472, 2015.

[122] J.-S. Tian, G.-J. Peng, Y.-F. Wu et al., "A GC-MS urinary quantitative metabolomics analysis in depressed patients treated with TCM formula of Xiaoyaosan," Journal of Chromatography B, vol. 1026, pp. 227-235, 2016.

[123] A. Zhang, H. Sun, and X. Wang, "Recent highlights of metabolomics for Traditional Chinese Medicine," Pharmazie, vol. 67, no. 8, pp. 667-675, 2012.

[124] S.-S. Li, "The Proteomics: a new tool for Chinese medicine research," American Journal of Chinese Medicine, vol. 35, no. 6, p. 923, 2007.

[125] Y. Quan, B. Li, Y.-M. Sun, and H.-Y. Zhang, "Elucidating pharmacological mechanisms of natural medicines by biclustering analysis of the gene expression profile: A Case Study On Curcumin and Si-Wu-Tang," International Journal of Molecular Sciences, vol. 16, no. 1, pp. 510-520, 2015.

[126] H. Y. Fang, S. B. Chen, D. J. Guo, S. Y. Pan, and Z. L. Yu, "Proteomic identification of differentially expressed proteins in curcumin-treated MCF-7 cells," Phytomedicine, vol. 18, no. 8-9, pp. 697-703, 2011.

[127] X. Z. Cai, W. Y. Huang, Y. Qiao et al., "Inhibitory effects of curcumin on gastric cancer cells: a proteomic study of molecular targets," Phytomedicine, vol. 20, no. 6, pp. 495-505, 2013.

[128] Y. Lao, X. Wang, N. Xu, H. Zhang, and H. Xu, "Application of proteomics to determine the mechanism of action of traditional Chinese medicine remedies," Journal of Ethnopharmacology, vol. 155, no. 1, pp. 1-8, 2014.

[129] D.-F. Wei, Y.-X. Wei, W.-D. Cheng et al., "Proteomic analysis of the effect of triterpenes from Patrinia heterophylla on leukemia K562 cells," Journal of Ethnopharmacology, vol. 144, no. 3, pp. 576-583, 2012.

[130] H. Sun, A. Zhang, G. Yan et al., "Proteomics study on the hepatoprotective effects of traditional Chinese medicine formulae Yin-Chen-Hao-Tang by a combination of two-dimensional polyacrylamide gel electrophoresis and matrix-assisted laser desorption/ionization-time of flight mass spectrometry," Journal of Pharmaceutical and Biomedical Analysis, vol. 75, pp. 173179, 2013.
[131] H.-Y. Lo, C.-C. Li, H.-C. Huang, L.-J. Lin, C.-Y. Hsiang, and T.-Y. Ho, "Application of transcriptomics in Chinese herbal medicine studies," Journal of Traditional and Complementary Medicine, vol. 2, no. 2, pp. 105-114, 2012. 


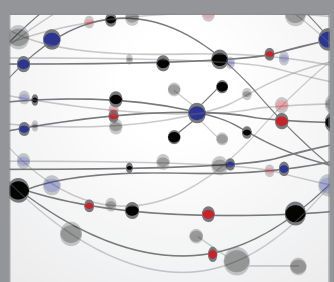

The Scientific World Journal
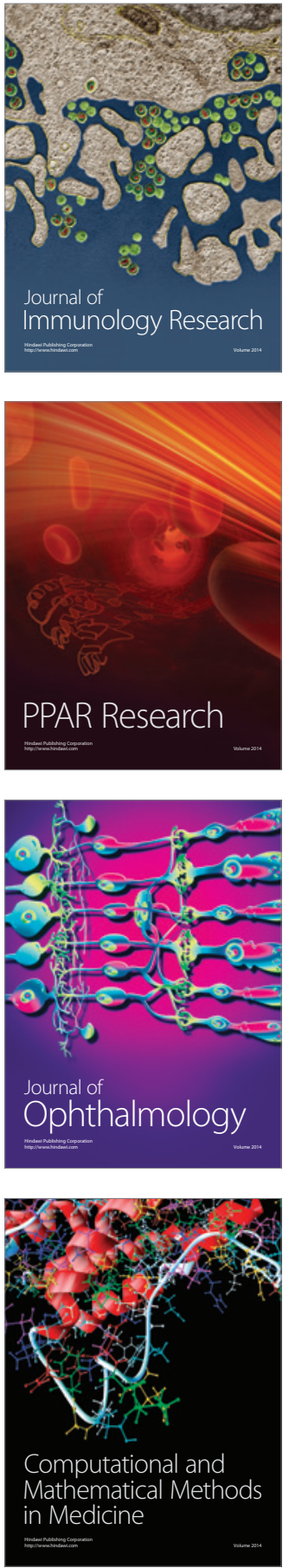

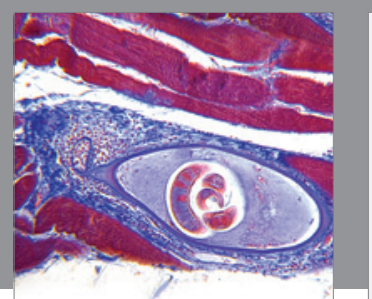

Gastroenterology Research and Practice
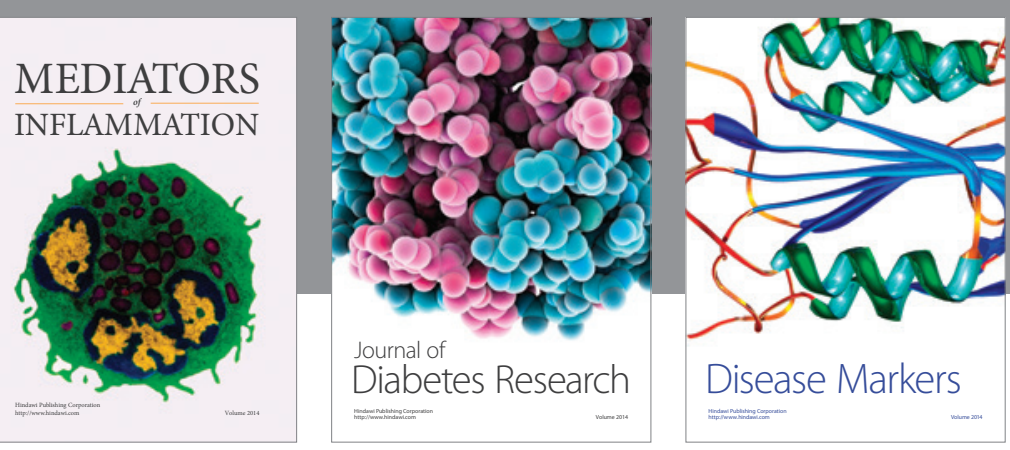

Disease Markers

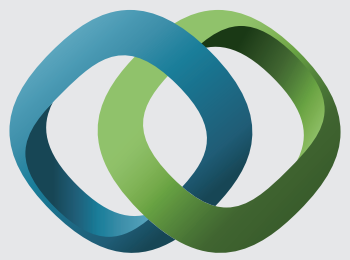

\section{Hindawi}

Submit your manuscripts at

https://www.hindawi.com
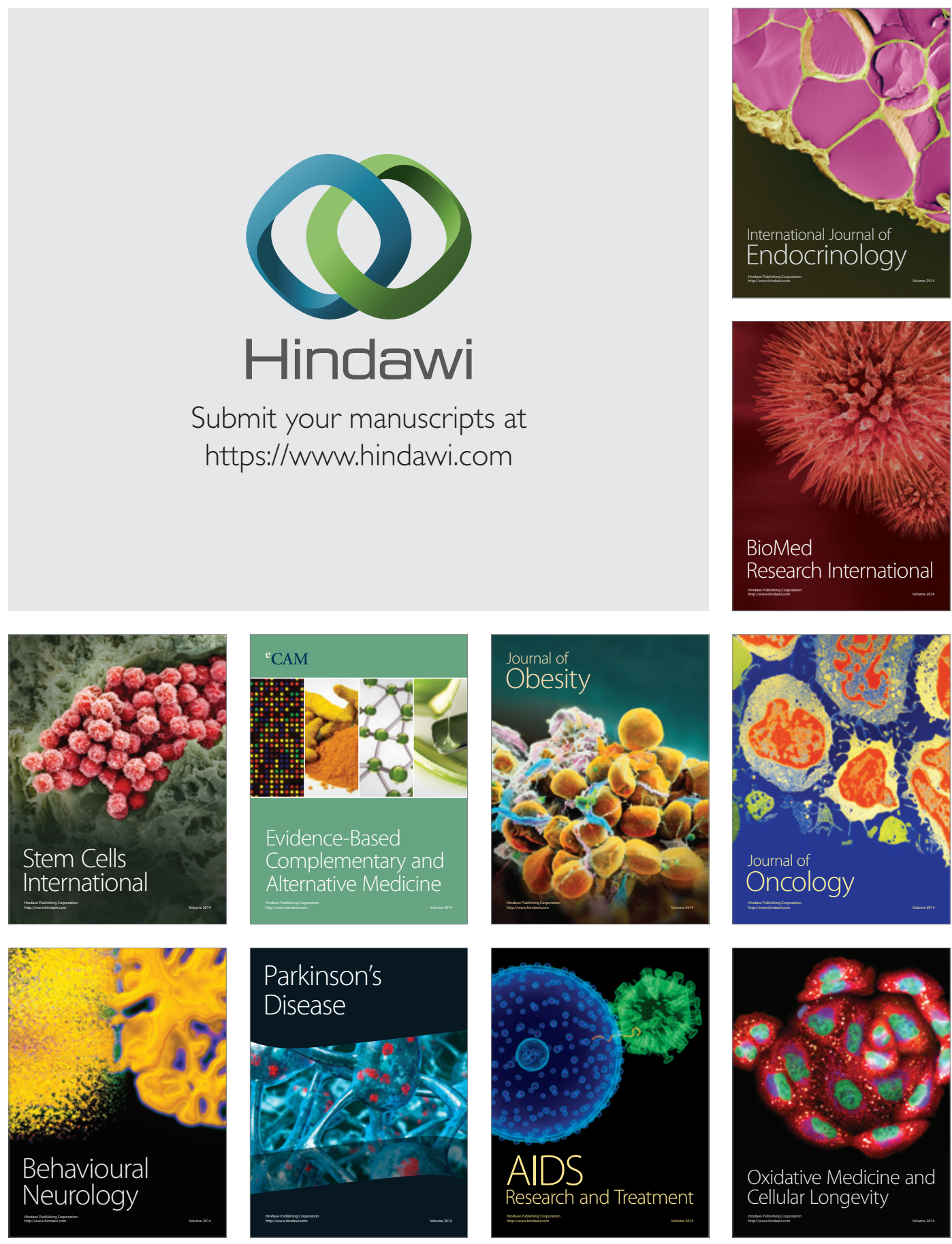